PRICE AND VOLUME MEASURES IN

THE SYSTEM OF NATIONAL ACCOUNTS

W. Erwin Diewert

Working Paper No. 5103

\author{
NATIONAL BUREAU OF ECONOMIC RESEARCH \\ 1050 Massachusetts Avenue \\ Cambridge, MA 02138 \\ May 1995
}

Financial support through a grant from the Social Services and Humanities Research Council of Canada is gratefully acknowledged. This paper is part of NBER's research program in Productivity. Any opinions expressed are those of the author and not those of the National Bureau of Economic Research.

() 1995 by W. Erwin Diewert. All rights reserved. Short sections of ext, not to exceed two paragraphs, may be quoted without explicit permission provided that full credit, including $(\odot$ notice, is given to the source. 


\title{
PRICE AND VOLUME MEASURES IN \\ THE SYSTEM OF NATIONAL ACCOUNTS
}

\begin{abstract}
The paper is an extensive review of chapter 16 in the System of National Accounts, 1993 written by Peter Hill. The basic principles for measuring price and quantity change in the National Accounts are explained. The paper also presents some new material on the consistency of superlative indexes with indexes which are additive in their components. Some new material on the treatment of quality change is also presented which indicates that traditional Statistical Agency treatments of this issue will lead to upward bias in price indexes. The literature on sources of bias in consumer price indexes is also reviewed.
\end{abstract}

W. Erwin Diewert

Department of Economics

University of British Columbia

Vancouver, BC V6T 1Z1

CANADA

and NBER 
PRICE AND VOLUME MEASURES IN THE SYSTEM OF NATIONAL ACCOUNTS

W.E. Diewert*

\section{Introduction}

This paper is a review of Chapter 16 in the System of National Accounts, 1993 entitled "Price and Volume Measures" which was written by Peter Hill [1993]. Sections 2 to 11 below will provide a brief review of the major topics that were covered in Chapter 16 along with some references to the literature. A decision was made not to include references in the new System of National Accounts, but this is rather unfair to the reader who may want to explore a particular topic at greater length. Thus we hope that the present paper will serve as a useful supplement to Chapter 16 .

The next two sections of this paper deal with topics that were not discussed in Chapter 16. Section 12 below provides an introduction to the recent literature on sources of bias in consumer price indexes while section 13 lists a number of price measurement and index number problems that were not considered in Chapter 16. Section 14 concludes.

We complete this section by listing some important books and surveys on index number theory. General works on index number theory include Lowe [1823], Frisch [1936], Stone [1956], Hill [1988], Turvey [1989] and Diewert [1981] [1987] [1993a]. There are two main approaches to index number theory: the test approach and the economic approach. References to the test approach include Walsh [1901] [1921a] [1921b] [1924], Fisher [1911] [1921] [1922], Eichhorn [1976] [1978], Eichhorn and Voeller [1976], Dalén [1992], Diewert [1992a] and Balk [1995]. References to the economic approach to index number theory include Konüs [1924], Konüs and Byushgens [1926], Hicks [1940] [1981], Samuelson [1947; 146-163], Allen [1949] [1975], Malmquist [1953], Pollak [1971] [1989], Afriat [1972] [1977], Fisher and Shell [1972], Samuelson and Swamy [1974] and Diewert [1976] [1978] [1980] [1983a] [1983b]. 


\section{Values, Prices and Quantities}

In this section, we discuss Hill's definitions of price and volume indexes. However, first we introduce some notation. ${ }^{1}$ Suppose that the task at hand is to construct price and volume indexes for $\mathrm{N}$ commodities over $\mathrm{T}+1$ periods. The base period is period 0 . The price, quantity and value of commodity $i$ in period $t$ is $p_{i}^{t}, q_{i}^{t}$ and $v_{i}^{t}=p_{i}^{t} q_{i}^{t}$ respectively for $i=1, \ldots, N$ and $t=1, \ldots, T$. Hill [1993; 381] defined a price (volume) index as a weighted average of the proportional changes in the prices $p_{i}^{t} / p_{i}^{0}$ (quantities $q_{i}^{t} / q_{i}^{0}$ ) of a specified set of goods and services between two periods of time. Later, Hill [1993; 382] regarded the price and volume indexes between periods 0 and $t$ as functions of the $4 \mathrm{~N}$ prices and quantities that pertain to the two periods under consideration. Thus defining the period $t$ vectors of prices and quantities by $p^{t}=\left[p_{1}^{t}, \ldots, p_{N}^{t}\right]$ and $q^{t}=\left[q_{1}^{t}, \ldots, q_{N}^{t}\right]$ for $t=0$, $1, \ldots, T$, we denote a generic price index as $P\left(p^{0}, p^{t}, q^{0}, q^{0}\right)$ and a generic volume or quantity index as $\mathrm{Q}\left(\mathrm{p}^{0}, \mathrm{p}^{1}, \mathrm{q}^{0}, \mathrm{q}^{\mathrm{t}}\right)$. It is also evident that Hill [1993; 382] assumed that the price and volume indexes should satisfy the following conservation of value equation: ${ }^{2}$

(1) $\quad P\left(p^{0}, p^{1}, q^{0}, q^{1}\right) Q\left(p^{0}, p^{1}, q^{0}, q^{1}\right)=p^{1} \cdot q^{1 / p^{0}} \cdot q^{0}$.

By inspecting equation (1), we see that the price and volume indexes, $P$ and $Q$, represent decompositions of the value change between periods 0 and $t, p^{t} \cdot q^{1 / p^{0}} \cdot q^{0}$, into a price change component $\mathbf{P}$ and a quantity change component $\mathbf{Q}$.

Hill $[1993 ; 381]$ introduced the rather odd term "volume index" in place of the more usual term "quantity index" to distinguish his definition of a volume index (as a weighted average of quantity relatives) from the sum of the quantities, $\Sigma_{i=1}^{N} q_{i}^{t}$. It appears that Hill wanted to distinguish what is normally called a bilateral quantity index $Q\left(p^{0}, p^{t}, q^{0}, q^{\dagger}\right)$ from what Eichhorn [1978; 140-146] called a quantity level, which is a function $Q^{*}\left(p^{t}, q^{t}\right)$ that simply aggregates the quantities $q^{t} \equiv\left[q_{1}^{t}\right.$, $\left.\ldots, q_{N}^{i}\right]$ that pertain to a single period $t$.

We turn now to Hill's discussion of bilateral price and volume indexes in the time series context. 


\section{Intertemporal Index Numbers of Prices and Volumes}

In this section, Hill [1993; 381-384] discussed the problems involved in choosing functional forms for the price and volume indexes $\mathrm{P}$ and $\mathrm{Q}$ in the context of aggregating up the microeconomic price and quantity information that pertains to a subset of the economy under consideration for time periods 0 and $t$. Hill noted that the most commonly used price indexes are the Laspeyres [1871] and Paasche [1874] price indexes defined as follows:

$$
\begin{aligned}
& P_{L}\left(p^{0}, p^{t}, q^{0}, q^{t}\right) \equiv p^{t} \cdot q^{0} / p^{0} \cdot q^{0}=\Sigma_{i=1}^{N} s_{i}^{0}\left(p_{i}^{i} / p_{i}^{0}\right) ; \\
& P_{P}\left(p^{0}, p^{t}, q^{0}, q^{t}\right) \equiv p^{t} \cdot q^{t} / p^{0} \cdot q^{l}=\left[\Sigma_{i=1}^{N} s_{i}^{i}\left(p_{i}^{t} / p_{i}^{0}\right)^{-1}\right]^{-1}
\end{aligned}
$$

where $s_{i}^{t} \equiv p_{i}^{t} q_{i}^{t} / p^{t} \cdot q^{t}$ is the share of commodity $i$ in period $t$ expenditure on the commodities. Notice that the price indexes defined by (2) and (3) can be viewed as expenditure share weighed arithmetic and harmonic averages of the price ratios $\mathrm{p}_{i}^{\mathrm{i}} / \mathrm{p}_{\mathrm{i}}^{0}$, facts first demonstrated by Walsh [1901; 559] and Fisher $[1911 ; 397-398][1922 ; 60]$. Hill also noted that the two most commonly used quantity or volume indexes are the Paasche and Laspeyres quantity indexes defined by:

$$
\begin{aligned}
& Q_{p}\left(p^{0}, p^{t}, q^{0}, q^{\prime}\right) \equiv p^{i} \cdot q^{t} / p^{i} \cdot q^{0}=\left[\Sigma_{i=1}^{N} s^{4}\left(q_{i}^{t} / q_{i}^{0}\right)^{-1}\right]^{-1} ; \\
& Q_{L}\left(p^{0}, p^{l}, q^{0}, q^{\prime}\right) \equiv p^{0} \cdot q^{i} / p^{0} \cdot q^{0}=\Sigma_{i=1}^{N} s_{i}^{0}\left(q_{i}^{t} / q_{i}^{0}\right) .
\end{aligned}
$$

Note that the indexes defined by (4) and (5) can be viewed as weighted harmonic and arithmetic averages of the quantity ratios $q_{i}^{i} / q_{i}^{0}, i=1, \ldots, N$.

Hill [1993; 382] observed that the product of the Laspeyres price index and the Paasche quantity index and the product of the Paasche price index and the Laspeyres quantity index satisfied the product test (1); i.e., we have

$$
\begin{aligned}
& P_{L}\left(p^{0}, p^{t}, q^{0}, q^{t}\right) Q_{P}\left(p^{0}, p^{t}, q^{0}, q^{l}\right)=p^{l} \cdot q^{t} / p^{0} \cdot q^{0} ; \\
& P_{P}\left(p^{0}, p^{t}, q^{0}, q^{q}\right) Q_{L}\left(p^{0}, p^{l}, q^{0}, q^{l}\right)=p^{l} \cdot q^{l} / p^{0} \cdot q^{0} .
\end{aligned}
$$

Hill $[1993 ; 383]$ indicated that whenever the price and quantity relatives or ratios, $\mathrm{p}_{\mathrm{i}}^{\mathrm{i}} / \mathrm{p}_{\mathrm{i}}^{0}$ and $q_{i}^{t} / q_{i}^{0}$, were negatively correlated (the usual case), then the Laspeyres price index would be above the Paasche price index (and vice versa for quantity indexes); i.e., we would have ${ }^{3}$ 
$\mathbf{P}_{\mathbf{p}}\left(\mathbf{p}^{0}, \mathbf{p}^{\mathbf{l}}, \mathbf{q}^{0}, \mathbf{q}^{\mathbf{q}}\right)<\mathbf{P}_{\mathrm{L}}\left(\mathbf{p}^{0}, \mathbf{p}^{\mathbf{l}}, \mathbf{q}^{0}, \mathbf{q}^{\mathbf{l}}\right)$

At this point, Hill introduced the economic approach to index number theory:

"From the point of view of economic theory, the observed quantities may be assumed to be functions of the prices, as specified in some utility or production function. Assuming that a consumer's expenditures are related to an underlying utility function, a cost of living index may then be defined as the ratio of the minimum expenditures required to enable a consumer to attain the same level of utility under the two sets of prices."

Hill [1993; 383]

The above verbal definition of a cost of living index may be put into a more concrete form as follows. Let the consumer's utility function (or the producer's production function) be denoted by $f\left(q_{1}, \ldots, q_{N}\right) \equiv f(q)$. Define the consumer's expenditure (or the producer's cost) function $\mathrm{C}$ as the solution to the following cost minimization problem:

$$
C(u, p) \equiv \min _{q}\{p q: f(q) \geq u\}
$$

where $\mathbf{p} \equiv\left(\mathrm{p}_{1}, \ldots, \mathrm{p}_{\mathrm{N}}\right)$ is a vector of positive commodity prices that the consumer (or producer) faces and $u$ is a reference utility (or output) level that must be attained. The Konüs [1924] price index between periods 0 and $t$ for reference utility (or output) level $u$ is then defined as

$$
P_{K}\left(p^{0}, p^{i}, u\right) \equiv C\left(u, p^{i}\right) / C\left(u, p^{q}\right)
$$

Hill [1993; 383] went on to state that the Laspeyres price index $P_{L}$ defined earlier by (2) provides an upper bound to the unobservable theoretical Konüs price index when the reference utility level is chosen to be the consumer's base period utility $u^{0}=f\left(q^{0}\right)$ and the Paasche price index $P_{p}$ defined by (3) provides a lower bound to the Konüs price index when the reference utility level is chosen to be the consumer's period $t$ level of utility $u^{t}=f\left(q^{\prime}\right)$; i.e., we have the following bounds, due originally to Konüs $[1924 ; 17-19]$ :

$$
\begin{aligned}
& P_{K}\left(p^{0}, p^{t}, u^{0}\right) \leq P_{L}\left(p^{0}, p^{t}, q^{0}, q^{1}\right) \\
& P_{K}\left(p^{0}, p^{t}, u^{t}\right) \geq P_{P}\left(p^{0}, p^{t}, q^{0}, q^{t}\right) .
\end{aligned}
$$

Hill further noted that if preferences are homothetic (i.e., the underlying utility or aggregator ${ }^{4}$ function is a monotonic transform of a linearly homogeneous function), then the Konüs price index 
$P_{K}\left(p^{0}, p^{t}, u\right)$ is independent of $u$ and hence $P_{L}$ and $P_{P}$ will provide bounds to the underlying unobservable Konüs price index..$^{5}$

At this point, Hill [1993; 384] introduced Irving Fisher's [1921] [1922] ideal price and quantity indexes, $P_{F}$ and $Q_{F}$, which are the geometric means of the corresponding Paasche and Laspeyres price and quantity indexes:

$$
\begin{aligned}
& P_{F}\left(p^{0}, p^{1}, q^{0}, q^{\prime}\right) \equiv\left[P_{L}\left(p^{0}, p^{t}, q^{0}, q^{i}\right) P_{p}\left(p^{0}, p^{t}, q^{0}, q^{\prime}\right)\right]^{1 / 2} \\
& Q_{F}\left(p^{0}, p^{\prime}, q^{0}, q^{\prime}\right)=\left[Q_{L}\left(p^{0}, p^{l}, q^{0}, q^{\prime}\right) Q_{p}\left(p^{0}, p^{l}, q^{0}, q^{l}\right)\right]^{1 / 2} \text {. }
\end{aligned}
$$

Hill noted that Fisher $[1922 ; 63]$ advocated the use of (13) and (14) because he initially thought that they were the only pair of indexes that satisfied Fisher's three reversal (or symmetry) tests: (i) commodity reversal (the indexes are invariant to the ordering of the commodities); (ii) time reversal (the index numbers going from period $t$ to 0 are the reciprocals of the index numbers going from period 0 to $t$ ) and (iii) factor reversal (the functional form for the quantity index is the same as the functional form for the price index except that the roles of prices and quantities are reversed ${ }^{7}$ ).

Hill [1993; 384] also looked favorably on the Törnqvist [1936] or translog price and volume indexes, $P_{T}$ and $Q_{T}$, defined as follows:

$$
\begin{aligned}
& P_{\mathrm{T}}\left(\mathbf{p}^{0}, \mathrm{p}^{\mathrm{t}}, \mathrm{q}^{0}, \mathrm{q}^{\mathrm{l}}\right)=\Pi_{i=1}^{N}\left(p_{i}^{t} / p_{i}^{0}\right)^{(1 / 2)\left(s_{i}^{0}+s_{i}^{i}\right)} ; \\
& \mathrm{Q}_{\mathrm{T}}\left(\mathrm{p}^{0}, \mathrm{p}^{\mathrm{t}}, \mathrm{q}^{0}, \mathrm{q}^{\mathrm{l}}\right)=\Pi_{i=1}^{N}\left(q_{i}^{i} / q_{i}\right)^{(1 / 2)\left(s_{i}^{0}+s_{i}^{i}\right)} ;
\end{aligned}
$$

where, as usual, $s_{i}^{t} \equiv p_{i}^{t} q_{i}^{t} / p^{t} \cdot q^{t}$ is the expenditure share of good $i$ in period $t$.

Hill [1993; 383-384] identified the Fisher and Törnqvist indexes as being exact indexes. Thus if the consumer's utility function is a homogeneous quadratic function, say $f(q)=(q \cdot A q)^{1 / 2}$ where $A$ is a symmetric matrix of constants, or if the consumer's unit cost function is a homogeneous quadratic function, say $c(p) \equiv C(1, p) \equiv(p \cdot B p)^{1 / 2}$ where $B$ is a symmetric matrix of constants, then under the assumption of optimizing behavior in periods 0 and $t$ (and the absence of corner solutions), we obtain:

$$
Q_{F}\left(p^{0}, p^{t}, q^{0}, q^{t}\right)=f\left(q^{t}\right) / f\left(q^{0}\right)
$$




$$
P_{F}\left(p^{0}, p^{i}, q^{0}, q^{i}\right)=c\left(p^{1}\right) / c\left(p^{0}\right)
$$

Thus the observable Fisher price and quantity indexes, $P_{F}$ and $Q_{F}$, are exactly equal to the theoretical Konüs price index $c\left(p^{0}\right) / c\left(p^{0}\right)$ (the ratio of unit costs) and to the theoretical quantity index $f\left(q^{0}\right) / f\left(q^{0}\right)$ (the ratio of utilities or outputs) respectively. The result (17) is originally due to the Russian mathematician Byushgens [1925]; see also Konüs and Byushgens [1926] who started the systematic study of exact indexes as well as Frisch [1936; 30], Wald [1939; 331], Samuelson [1947; 155], Afriat [1972; 45], Pollak [1971; 49] and Diewert [1976; 132]. Result (18) is due to Konüs and Byushgens [1926; 167-172] and Diewert $[1976 ; 132]$. Similarly, Diewert $[1976 ; 122]$ showed that the Törnqvist price index $\mathrm{P}_{\mathrm{T}}$ is exactly equal to the Konüs theoretical price index, provided that the consumer's cost function is translog and that the reference level of utility $u^{*}$ is chosen to be the geometric mean of the period 0 and $t$ levels of utility, $u^{0}$ and $u^{t}$; i.e., we have

$$
\mathbf{P}_{\mathrm{T}}\left(\mathbf{p}^{0}, \mathbf{p}^{\mathrm{t}}, \mathbf{q}^{0}, \mathrm{q}^{\mathrm{l}}\right)=\mathbf{P}_{\mathrm{K}}\left(\mathbf{p}^{0}, \mathrm{p}^{\mathrm{t}}, \mathrm{u}^{*}\right)
$$

where $u^{*} \equiv\left(u^{0} u^{1}\right)^{1 / 2}$. Diewert $[1976 ; 120]$ also showed that the Törnqvist quantity index $Q_{T}$ is exactly equal to the theoretical quantity index $f\left(q^{0}\right) / f\left(q^{0}\right)$ provided that the consumer is optimizing in both periods and that $f$ is a homogeneous translog aggregator function. ${ }^{9}$

What is the importance of the results (17) - (19)? Consider the following quotation:

"When the production possibilities being analyzed can be represented by a homogeneous translog production function, it can be shown that the Tornqvist index provides an exact measure of the underlying theoretic volume index. Thus the Törnqvist index, like the Fisher index, provides an exact measure under certain very specific circumstances. Both indices are examples of 'superlative' indices: i.e., indices that provide exact measures for some underlying functional form that is 'flexible,' the homogeneous quadratic and homogeneous translog functions being particular examples of such flexible functional forms."

Hill [1993; 384]

Diewert $[1974 ; 113]$ defined a flexible functional form as one that can provide a second order approximation to an arbitrary function (in the class of functions being considered). Diewert [1976; 117] defined a quantity index $Q\left(p^{0}, p^{t}, q^{0}, q^{0}\right)$ to be superlative if it is exact for a flexible linearly homogeneous aggregator function $f(q)$; i.e., we have $Q\left(p^{0}, p^{t}, q^{0}, q^{q}\right)=f\left(q^{0}\right) / f\left(q^{0}\right)$ where $f$ is flexible. 
Diewert [1976; 134] also defined a price index $P\left(p^{0}, p^{i}, q^{0}, q^{\prime}\right)$ to be superlative if it is exact for a flexible unit cost function $c(p)$; i.e., we have $P\left(p^{0}, p^{1}, q^{0}, q^{0}\right)=c\left(p^{1}\right) / c\left(p^{0}\right)$ where $c$ is flexible. The importance of superlative index number formulae is that: (i) they can be evaluated knowing only prices and quantities pertaining to the two periods under consideration (thus no econometric estimation is required) and (ii) they are likely to approximate underlying (unobservable) economic indexes rather well.

Hill [1993; 384] went on to suggest that the use of a superlative index number formula has some practical and conceptual disadvantages, the two most important being the following: (i) microeconomic prices and quantities for both periods under consideration are required to evaluate superlative indexes whereas the Laspeyres price index requires both price vectors and only base period quantities $^{10}$; (ii) the Fisher and Törnqvist quantity indexes are not additively consistent; i.e., they cannot be used to create an additive set of "constant price" subaggregates.

Hill's first criticism of superlative price indexes is undoubtedly valid in many situations where timeliness is required. However, several Statistical Agencies have managed to calculate Fisher or Törnqvist indexes. Examples include the following Agencies: (i) the Customs and Tariff Bureau of the Ministry of Finance in Japan has calculated Fisher ideal price and quantity indexes for Japanese exports and imports since 1955; (ii) the U.S. Bureau of Labor Statistics [1983] [1993] has used Törnqvist quantity indexes since 1983 to aggregate inputs and outputs in its measures of multifactor productivity for the U.S. economy; (iii) the U.S. Bureau of Economic Analysis has recently calculated Fisher ideal indexes for the years $1959-1990$ for the major components of U.S. Gross Domestic Product; see Triplett [1992] and Young [1992].

Hill addressed the problem of the lack of additive consistency of superlative quantity indexes in his discussion of chain indexes, so we defer discussion of this issue until the following section. Hill concluded his discussion of bilateral index number theory with the following words: 
"Thus economic theory suggests that, in general, a symmetric index that assigns equal weight to the two situations being compared is to be preferred to either the Laspeyres or Paasche indices on their own. The precise choice of superlative index -- whether Fisher, Törnqvist or other superlative index -- may be of only secondary importance as all the symmetric indices are likely to approximate each other, and the underlying theoretic index, fairly closely, at least when the index number spread between the Laspeyres and Paasche is not very great."

Hill [1993; 384]

In order to explain more precisely the meaning of the above quotation, it will be useful to list all of the known superlative indexes.

In addition to the superlative price and quantity indexes defined by (13) - (16) above, the following families of index number formulae have been shown to be superlative:

$$
\begin{aligned}
& Q_{r}\left(p^{0}, p^{t}, q^{0}, q^{i}\right) \equiv\left[\Sigma_{i=1}^{N} s_{i}^{0}\left(q_{i}^{t} / q_{i}^{g}\right)^{r / 2}\right]^{1 / r}\left[\Sigma_{n=1}^{N} s_{n}^{t}\left(q_{n}^{t} / q_{n}^{0}\right)^{-1 / 2}\right]^{-1 / r} ; \\
& P_{r}\left(p^{0}, p^{l}, q^{0}, q^{l}\right) \equiv\left[\Sigma_{i=1}^{N} s_{i}^{0}\left(p_{i}^{t} / p_{i}^{g}\right)^{r / 2}\right]^{1 / r}\left[\Sigma_{n=1}^{N} s_{n}^{t}\left(p_{n}^{l} / p_{n}^{g}\right)^{-r / 2}\right]^{-1 / r} ; \\
& Q_{\alpha}\left(p^{0}, p^{l}, q^{0}, q^{i}\right)=\left[p^{0} \cdot \alpha p^{l} \cdot q^{l}+p^{l} \cdot \alpha p^{0} \cdot q^{l}\right] /\left[p^{0} \cdot \alpha p^{l} \cdot q^{0}+p^{l} \cdot \alpha p^{0} \cdot q^{0}\right]
\end{aligned}
$$

where $s_{i}^{t} \equiv p_{i}^{t} q_{i}^{t} / p^{t} \cdot q^{t}$. The indexes $Q_{r}$ and $P_{r}$ defined by (20) and (21) are defined for each scalar parameter $r \neq 0$; the index $\mathrm{Q}_{\alpha}$ defined by (22) is defined for each nonnegative (and nonzero) vector of parameters $\alpha \equiv\left(\alpha_{1}, \ldots, \alpha_{\mathrm{N}}\right) . \mathrm{Q}_{\mathrm{r}}$ is the quadratic mean of order $\mathrm{r}$ quantity index which is exact for the quadratic mean of order $r$ aggregator function $f(q)=\left[\Sigma_{i=1}^{N} \Sigma_{j=1}^{N} a_{i j} q_{i}^{r / 2} q_{j}^{r / 2}\right]^{1 / r}$ (Diewert [1976; 129-132]); $P_{r}$ is the quadratic mean of order $r$ price index which is exact for the quadratic mean of order $r$ unit cost function $c(p) \equiv\left[\Sigma_{i=1}^{N} \Sigma_{j=1}^{N} b_{i j} p_{i}^{r / 2} p_{j}^{r / 2}\right]^{1 / r}$ (Diewert $\left.[1976 ; 130-134]\right)$; and $Q_{\alpha}$ is the normalized quadratic quantity index (with quantity weights vector $\alpha$ ) whose price index $P_{\alpha}\left(p^{0}, p^{t}, q^{0}, q^{\prime}\right.$ ) $\equiv p^{t} \cdot q^{t} / p^{0} \cdot q^{0} Q_{\alpha}\left(p^{0}, p^{t}, q^{0}, q^{\prime}\right)$ is exact for the normalized quadratic unit cost function ${ }^{11} c(p) \equiv[b \cdot p$ $\left.+(1 / 2)(\mathrm{p} \cdot \alpha)^{-1} \mathrm{p} \cdot \mathrm{Ap}\right]$ where $\mathrm{b}$ is a parameter vector and $\mathrm{A}$ is a symmetric matrix of parameters (Diewert [1992b; 575-576]). Diewert [1992b; 577] also showed that if we set $\alpha=q^{0}$ or $q^{t}$, then $Q_{\alpha}$ defined by (22) reduces to the following more recognizable indexes: ${ }^{12}$

$$
\begin{aligned}
& Q_{q} 0\left(p^{0}, p^{t}, q^{0}, q^{t}\right)=(1 / 2) Q_{L}+(1 / 2) Q_{p} ; \\
& Q_{q^{l}}\left(p^{0}, p^{t}, q^{0}, q^{\prime}\right)=\left[(1 / 2) Q_{L}^{-1}+(1 / 2) Q_{p}^{-1}\right]^{-1}
\end{aligned}
$$


where $Q_{L} \equiv Q_{L}\left(p^{0}, p^{t}, q^{0}, q^{i}\right)$ and $Q_{p} \equiv Q_{p}\left(p^{0}, p^{t}, q^{0}, q^{\prime}\right)$ are the familiar Laspeyres and Paasche quantity indexes defined by (5) and (4) above. Thus using (23), (13) and (24), we see that the arithmetic, geometric and harmonic means of the Laspeyres and Paasche quantity indexes are all superlative indexes.

By inspecting (13) - (16) and (20) - (22), we see that all superlative index number formulae do treat the data pertaining to the two periods in a symmetric fashion in the sense that Walsh's

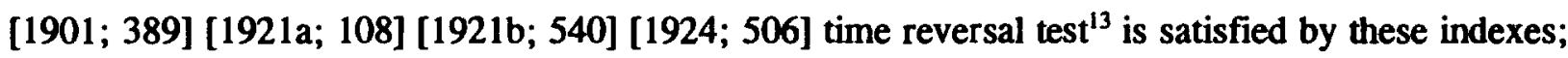
i.e., we have

$$
\begin{aligned}
& P\left(p^{l}, p^{0}, q^{l}, q^{0}\right)=1 / P\left(p^{0}, p^{l}, q^{0}, q^{l}\right) \\
& Q\left(p^{1}, p^{0}, q^{1}, q^{0}\right)=1 / P\left(p^{0}, p^{1}, q^{0}, q^{\prime}\right)
\end{aligned}
$$

if $P$ and $Q$ are superlative. ${ }^{14}$ However, the weighting of the quantity ratios $q_{i}^{t} / q_{i}^{0}$ in $(20)$ and of the price ratios $\mathrm{p}_{\mathrm{i}}^{\mathrm{t}} / \mathrm{p}_{\mathrm{i}}^{0}$ in (21) is quite complex. Moreover, the family of superlative quantity indexes $\mathrm{Q}_{\alpha}$ defined by (22) cannot even be written as simple functions of the quantity ratios $q_{i}^{t} / q_{i}^{0}$.

Even though the above superlative index number formulae look quite different, it can be shown that they approximate each other to the second order around any point where the two price vectors are proportional and the two quantity vectors are proportional. ${ }^{16}$ Thus the actual choice of a superlative index is relatively unimportant numerically as Hill suggested in the last quotation above.

Finally, Diewert [1978; 888] defined an index number formula to be pseudo-superlative if its second order Taylor series approximation around an equal price and quantity point (i.e., $p^{0}=p^{t}$ and $q^{0}=q^{\prime}$ ) coincided with the corresponding second order Taylor series approximation to a superlative index. Thus pseudo-superlative index numbers will be numerically close to superlative index numbers, at least in the time series context where prices and quantities typically change slowly over time. Diewert $[1978 ; 897]$ showed that any differentiable symmetric mean ${ }^{17}$ of the Paasche and Laspeyres price (quantity) indexes is a pseudo-superlative price (quantity) index. ${ }^{18}$

We turn now to Hill's discussion of chain indexes. 


\section{Chain Indexes}

In this section, ${ }^{19}$ Hill $[1993 ; 385-390]$ contrasted the common Statistical Agency practice of constructing fixed base Laspeyres volume indexes using the formula (5) with the use of chain indexes. ${ }^{20}$ The chain system measures the change in output going from one period to a subsequent period using a bilateral index number formula involving the prices and quantities pertaining to the two adjacent periods. These one period rates of change are then cumulated to yield the relative levels of output over the entire period under consideration. Thus if the bilateral quantity index is $Q$, the chain system generates the following pattern of relative aggregate quantities for the first three periods:

$$
\text { 1, } Q\left(p^{0}, p^{1}, q^{0}, q^{1}\right), Q\left(p^{0}, p^{1}, q^{0}, q^{1}\right) Q\left(p^{1}, p^{2}, q^{1}, q^{2}\right)
$$

Thus the output growth rate going from period $t$ and $t+1$ is always defined by $Q\left(p^{t}, p^{t+1}, q^{t}, q^{t+1}\right)$ in the chain system.

Comparing the fixed base system (5) with the chain system (27), Hill noted that the chain system will not preserve the additivity of the components of the index whereas the fixed base Laspeyres quantity index (5) will. Since many users of the national accounts find it extremely convenient to have additive real components for their aggregate of interest, this lack of additivity makes the chain system less desirable.

However, the fixed base Laspeyres quantity index (5) cannot be used forever: eventually, the base period prices $p^{0} \equiv\left[p_{1}^{0}, \ldots, p_{N}^{0}\right]$ are so far removed from the current period prices $p^{t} \equiv\left[p_{1}^{t}\right.$, $\left.\ldots, \mathrm{p}_{\mathrm{N}}^{\mathrm{t}}\right]$ that the base must be changed. ${ }^{21}$ As soon as the base is changed, Hill $[1993 ; 385]$ pointed out that additivity is lost. Thus as a practical matter, additivity of components of a volume index cannot be maintained for long periods of time.

Hill $[1993 ; 387-388]$ noted the main advantage of the chain system: under normal conditions, chaining will reduce the spread between the Paasche and Laspeyres indexes and hence the use of either a chained Paasche or Laspeyres index should more closely approximate a superlative index 
like the Fisher ideal and hence approximate the underlying economic index. ${ }^{22}$

Hill [1993; 388], drawing on the earlier research of Szulc [1983] and Hill [1988; 136-137], also noted that it is not appropriate to use the chain system when prices oscillate (or "bounce" to use Szulc's [1983; 548] term). This phenomenon can occur in the context of regular seasonal fluctuations or in the context of price wars. However, in the context of roughly monotonically changing prices and quantities, Hill [1993; 389] recommended the use of chained Fisher or Törnqvist indexes.

We conclude this section with an observation about superlative indexes and additivity ${ }^{23}$ : there are superlative quantity indexes which preserve additivity for two periods (but only two periods). Examination of (22) shows that for any nonnegative, nonzero vector of quantity weights $\alpha \equiv\left[\alpha_{1}\right.$, $\left.\ldots, \alpha_{N}\right]$, the normalized quadratic quantity index with weights $\alpha, Q_{\alpha}$, is additive over its components for periods 0 and $t$. The ith constant price is $\left(\sum_{n=1}^{N} p_{n}^{0} \alpha_{n}\right) p_{i}^{t}+\left(\sum_{n=1}^{N} p_{n}^{i} \alpha_{n}\right) p_{i}^{0}$.

There is one other superlative index number formula that preserves additivity over two periods. Recall the quadratic mean of order $r$ price index $P_{r}$ defined by (21) above. If we set $r=$ 1 and divide the value ratio $p^{t} \cdot q^{2} / p^{0} \cdot q^{0}$ by $P_{1}\left(p^{0}, p^{t}, q^{0}, q^{1}\right)$, we obtain the following quantity index due to Walsh $[1901 ; 105][1921 \mathrm{a} ; 101]$ :

$$
Q_{w}\left(p^{0}, p^{t}, q^{0}, q^{n}\right)=\Sigma_{i=1}^{N}\left(p_{i}^{0} p_{i}^{i}\right)^{1 / 2} q_{i}^{i} / \Sigma_{n=1}^{N}\left(p_{n}^{0} p_{i}^{t}\right)^{1 / 2} q_{n}^{0}
$$

The above Walsh quantity index preserves additivity over periods 0 and $t$. The ith constant price is $\left(\mathrm{p}_{\mathrm{i}}^{0} \mathrm{p}_{\mathrm{i}}^{\mathrm{t}}\right)^{1 / 2}$, the square root of the product of the period 0 and period $\mathrm{t}$ prices for commodity $\mathrm{i}$. Thus if Statistical Agencies wanted to provide superlative indexes for their users that were additive over the current period $t$ and the previous period, the use of the rather simple Walsh quantity index $\mathrm{Q}_{w}\left(\mathrm{p}^{\mathrm{t}-1}, \mathrm{p}^{\mathrm{t}}, \mathrm{q}^{\mathrm{t}-1}, \mathrm{q}^{\mathrm{t}}\right)$ is recommended over the somewhat more complex normalized quadratic quantity index $Q_{\alpha}\left(p^{t-1}, p^{t}, q^{t-1}, q^{t}\right) .^{24}$ 


\section{Volume Measures for Gross Value Added and GDP}

The material Hill [1993; 390-393] presented in this section extended his analysis of the previous section to the situation where some commodities are outputs and others are (intermediate) inputs. Intermediate inputs must be distinguished from primary inputs which are labour, capital, land and natural resources. Intermediate inputs are (non durable) inputs that were initially provided by other domestic or foreign producers. The nominal gross value added for an establishment, enterprise, industry or sector is defined to be the value of outputs produced minus intermediate inputs used by the production unit during the time period under consideration. Hill [1993; 391] defined a volume index for value added (real value added in standard terminology) using a quantity index such as the Paasche or Laspeyres quantity index defined by (4) or (5) above, except that in the present situation, the quantities of intermediate inputs used during the two periods under consideration have negative signs attached to them. ${ }^{25}$

Hill revisited the analysis of the previous section, which presented the tradeoff between chaining and additivity. However, in the present context, Hill was even more emphatic on the need for chaining as the following quotations indicate:

"If relative prices change, relative quantities will be adjusted in response. A process of production which is efficient at one set of prices may not be very efficient at another set of relative prices. If the other set of prices is very different the inefficiency of the process may reveal itself in a very conspicuous form, namely negative gross value added."

Hill [1993; 390]

"Sooner or later the base year for fixed weight Laspeyres volume indices and their associated constant price series has to be updated because the prices of the base year become increasingly irrelevant. When the base year is updated, series on the old base have to be linked to those on the new base. Thus, sooner or later additivity is lost as a result of linkage (assuming the rebasing is not carried backwards). Long runs of data, therefore, almost inevitably involve some form of chain indices. Annual chaining is simply the limiting case in which rebasing is carried out each year instead of every five or ten years."

Hill [1993; 393]

To minimize the problem of meaningless or negative real value added, Hill $[1993 ; 392]$ recommended the use of Fisher ideal chained volume indexes (or chained Laspeyres volume indexes 
as an acceptable alternative), with the proviso that the chain indexes be used to measure only year to year movements and not quarter to quarter movements. To meet the needs of additivity users, Hill [1993; 393] also recommended that disaggregated constant price series should be published in addition to the chain indexes for the main aggregates. However, if users demand additivity, then it may be better to use the Walsh quantity index $Q_{w}\left(p^{1-1}, p^{\prime}, q^{1-1}, q^{\prime}\right)$ (recall (28) above) as the linking superlative index number formula since this index will preserve the additivity of its components over periods $\mathrm{t}-1$ and $\mathrm{t}$.

Elsewhere in the System of National Accounts, 1993 (United Nations [1993, 127]), Hill stated that intermediate inputs are normally valued at purchasers' prices and outputs at basic prices, which are prices before taxes on outputs are added and subsidies on products are subtracted; i.e., a basic output price represents the revenue from selling one unit of a product that the producer actually receives. This is the correct treatment of prices from the viewpoint of the economic theory of the producer. However, the existence of specific taxes on intermediate inputs (such as the former Canadian Manufacturers Sales Tax) as well as the existence of complex systems of value added taxation make the calculation of value added very complicated. These indirect taxes mean that in general the output price for a commodity will not equal the corresponding intermediate input price; taxes will create wedges between these two prices. It is important for economic analysts to have information on the commodity incidence of these indirect taxes that fall within the confines of the production sector so that their effects on production efficiency can be determined. The identification and appropriate treatment of taxes is a topic that deserves high priority in the next revision of the System of National Accounts.

References to the literature on output indexes and the deflation of value added include Bowley [1921], Malmquist [1953], Stone [1956], Arrow [1974], Samuelson and Swamy [1974; 588-592], Sato [1976; 438], Archibald [1977], Diewert [1980; 455-464] [1983b; 1054-1077] and Caves, Christensen and Diewert [1982a] [1982b]. 


\section{International Price and Volume Indexes}

Hill [1993; 393-397] drew on his earlier work (Hill [1982] [1984]) on international comparisons in writing an excellent summary of the current state of thought on how to make international (and interregional) comparisons.

Hill started his exposition by noting that bilateral index number theory can be used to compare price and volume levels between countries:

"It is possible to compare prices and volumes between countries using the same general methodology as for intertemporal comparisons within a single country. International volume indices are needed in order to compare levels of productivity or standards of living in different countries, while comparisons of prices can be used to measure purchasing power parities between different currencies."

Hill [1993; 393]

Hill $[1993 ; 393-395]$ went on to note that international (or multilateral) comparisons differ from intertemporal (or bilateral) comparisons for at least five reasons:

(i) There can be large differences in the size of countries being compared. ${ }^{26}$ This makes it more difficult to apply the economic approach to index number theory, which relies on assumptions about the homogeneity of tastes or technology.

(ii) Countries are modifiable units. They can be partitioned into smaller countries or they can be merged into larger blocks. This raises issues of weighting; i.e., comparing Canadian output with Mexican output in a North American multilateral framework should (perhaps) be invariant to whether the U.S. is treated as a single country or 50 States.

(iii) Price and quantity movements tend to be gradual in the intertemporal context (and this makes the application of the chain method attractive). This is not the case in the international context. Therefore, the choice of index number formula will matter more in the multilateral context. Hill [1993; 393] also pointed out that there is no natural counterpart to the chain principle in the multilateral context. ${ }^{27}$

(iv) Hill [1993; 394$]$ noted that it is more difficult to collect price information in the multilateral context. In the intertemporal context, the price of commodity $n$ in period $t, p_{n}^{l}$, can be 
in any unit of measurement, as long as that unit is not changed over time. In the multilateral context, the international prices for commodity $n, p_{n}^{s}$, must be measured in exactly the same physical units across countries $i$. This harmonization of units of measurement may be very difficult to do across country Statistical Agencies. Moreover, the list of commodities to be sampled at the elementary level ${ }^{28}$ should be exactly the same across countries. This requirement for a standard list of representative commodities to be priced by all Statistical Agencies in the block of countries under consideration is impossible to meet if the countries are diverse.

(v) Finally, Hill [1993; 395] noted that price or volume indexes in the multilateral context typically are required to be transitive; $i . e .$, if we compare countries $\mathrm{i}$ and $\mathrm{j}$ directly, this comparison should be the same as if we were to compare $i$ with $\mathrm{k}$ and then $\mathrm{k}$ with $\mathrm{j}$. Put another way, no single country should play an asymmetric role in forming the system of multilateral indexes. Hill explained the difference between the intertemporal and multilateral situations as follows:

"Transitivity is not important in a time series context because time periods form an ordered sequence. For this reason, there is little interest in direct comparisons between all possible pairs of time periods. Direct comparisons tend to be confined either to comparisons with a selected base period, typically the first period in the sequence (leading to fixed base Laspeyres or Paasche indices) or to comparisons between consecutive time periods (leading to chain indices). Comparisons between other possible pairs of periods are not usually needed or undertaken."

Hill [1993; 395]

From the above list of difficulties, it can be seen that the choice of an appropriate multilateral index number formula is not a trivial problem.

Hill [1993; 395-397] finished his exposition of multilateral index number theory by listing two broad approaches to the choice of functional forms: (i) the block approach (or the average prices approach) and (ii) the binary approach. We will distinguish a third broad approach which is dual to the first approach: (iii) the average quantities approach. In order to explain these approaches, we need to introduce a bit of notation.

Suppose that we want to form price and quantity aggregates for $\mathrm{N}$ commodities over $\mathrm{J}$ countries. Denote the price and quantity vectors for country $j$ by $p^{j} \equiv\left[p_{1}^{j}, \ldots, p_{N}^{j}\right]$ and $q^{j} \equiv\left[q_{1}^{j}\right.$, 
$\ldots, q \mathrm{k}]$ for $j=1, \ldots, \mathrm{J}$. Denote a multilateral price index between countries $i$ and $j(j$ relative to i) by $\mathrm{P}^{\mathrm{ij}}$ and the corresponding multilateral quantity index by $\mathrm{Q}^{\mathrm{ij}}$. In general, these indexes will be functions of all bloc prices and quantities, $p^{1}, \ldots, p^{\mathrm{j}}$ and $q^{1}, \ldots, q^{\mathrm{J}}$. We assume that the $\mathrm{P}^{\mathrm{ij}}$ and $\mathrm{Q}^{\mathrm{ij}}$ satisfy the following counterpart to the product test (1):

(29) $P^{i j} Q^{i j}=p^{j} \cdot q^{j} / p^{i} \cdot q^{i}, 1 \leq i, j \leq J$.

Thus if $P^{i j}$ is defined, then (29) can be utilized to define $Q^{i j}$ and vice versa.

In the average prices method for making multilateral comparisons, a vector of world average prices $\overline{\mathbf{p}} \equiv\left[\tilde{\mathrm{p}}_{1}, \ldots, \overline{\mathrm{p}}_{\mathrm{N}}\right]$ must be defined. Once $\overline{\mathbf{p}}$ is defined, $Q^{\mathrm{ij}}$ is defined for all $1 \leq \mathrm{i}, \mathrm{j} \leq \mathrm{J}$ as follows:

(30) $\quad Q^{i j}\left(\bar{p}, q^{i}, q^{j}\right) \equiv \bar{p} \cdot q^{j} / \bar{p} \cdot q^{i}$.

Note that $Q^{i j}=Q^{i} / Q^{i}$ where $Q^{i} \equiv \overline{\mathbf{p}} \cdot q^{i}$ and $Q^{j}=\overline{\mathbf{p}} \cdot q^{j}$. These latter two indexes are additive across commodities, which explains the attractiveness of this class of indexes.

Various choices for $\overline{\mathbf{p}}$ have been suggested over the years, including the arithmetic means of country prices defined by

$$
\overline{\mathbf{p}}_{\mathrm{n}}=\Sigma_{\mathrm{j}=1}^{\mathrm{J}}(1 / \mathrm{J}) \mathrm{p}_{\mathrm{n}}^{\mathrm{j}}, \mathrm{n}=1, \ldots, \mathrm{N},
$$

and the geometric means of country prices defined by

$$
\overline{\mathbf{p}}_{\mathbf{n}}=\left[\Pi_{j=1}^{\mathrm{J}} \mathrm{p}_{\mathrm{n}}^{\mathrm{j}}\right]^{1 / J}, \mathbf{n}=1, \ldots, \mathrm{N} \text {. }
$$

The use of (32) was advocated by Walsh [1901; 398] (his double weighting method) and by Gerardi [1982; 403]. The use of (31) is an example of Fisher's [1922; 367] broadened base system.

Another more complex average prices method is the Geary [1958]-Khamis [1970] [1972] method. The nth average price is defined by

$$
\bar{p}_{n} \equiv \Sigma_{j=1}^{J}\left(q_{n}^{j} / \Sigma_{k=1}^{J} q_{n}^{h}\right)\left(p_{n}^{j} / P^{j}\right), n=1, \ldots, N
$$

where the country $\mathrm{j}$ purchasing power parity $\mathrm{P}^{\mathrm{j}}$ is defined as

$$
P^{j} \equiv p^{j} \cdot q^{j} / \bar{p} \cdot q^{j}, j=1, \ldots, J
$$

Equations (33) and (34) can be regarded as $\mathrm{N}+\mathrm{J}$ simultaneous equations (one equation is dependent) 
in the $\mathrm{N}$ components of $\tilde{\mathrm{p}}$ and the $\mathrm{P}, \mathrm{j}=1, \ldots, \mathrm{J}$. We need one additional normalization (such as $\left.P^{\prime}=1\right)$ to solve the system. Khamis [1970] [1972] showed that a unique solution always exists if prices and quantities are positive. Note that $\bar{p}_{\mathfrak{n}}$ can be regarded as a weighted arithmetic mean of the purchasing power parity adjusted prices for commodity $n, p_{n}^{j} / p^{j}$, across countries where the country $\mathrm{j}$ weight is its share of world output for commodity $\mathbf{n}$.

The average quantities method reverses the role of prices and quantities in the above method. Thus we now define a vector of block average quantities $\overline{\mathrm{q}} \equiv\left[\overline{\mathrm{q}}_{1}, \ldots, \overline{\mathrm{q}}_{\mathrm{N}}\right]$ and the price indexes $\mathrm{P}^{\mathrm{ij}}$ are defined in terms of $\bar{q}$ as follows:

$$
P^{i j}\left(\bar{q}, p^{i}, p^{j}\right) \equiv p^{j} \cdot \bar{q} / p^{i} \cdot \bar{q}, \quad 1 \leq i, j \leq J .
$$

Once the $P^{i j}$ are defined, the volume indexes $Q^{i j}$ can be defined residually using (29). Obvious choices for $\overline{\mathbf{q}}$ are the arithmetic and geometric means of block quantities:

$$
\begin{aligned}
& \bar{q}_{n} \equiv \Sigma_{j=1}^{J}(1 / J) q_{n}^{j} ; n=1, \ldots, N ; \\
& \bar{q}_{n} \equiv\left[\Pi_{j=1}^{J} q_{n}^{j}\right]^{1 / J} ; n=1, \ldots, N .
\end{aligned}
$$

The use of (36) was first suggested by Walsh [1901; 431] who called it Scrope's method with arithmetic weights. This method was also described by Ruggles [1967; 81], who called it the market basket method. The use of (37) was advocated by Walsh [1901; 398-399], who called it Scrope's method with geometric weights. The quantity indexes $Q^{i j}$ defined by (35) - (37) and (29) are not additive across commodities.

The final class of multilateral methods that we consider is what Hill $[1993 ; 396]$ called the binary approach. Using each country as the base country, bilateral indexes are used to provide alternative price and quantity aggregates for all countries in the block. These $\mathrm{J}$ sets of parities are then averaged (or blended to use Fisher's $[1922 ; 305]$ term) to form an invariant set of multilateral indexes. Fisher $[1922 ; 305]$ used an arithmetic average of the country specific parities while Gini $[1931 ; 12]$ used a geometric average. Both of these authors used the bilateral Fisher ideal indexes defined by (13) and (14) above as their basic bilateral formulae. It should be noted that Eltetö and 
Köves [1964] and Szulc [1964] also derived Gini's multilateral method using a least squares approach, which we explain below.

Write the multilateral price indexes $\mathrm{P}^{\mathrm{ij}}$ as $\mathrm{P}^{\mathrm{ij}}=\mathrm{P}^{\mathrm{j}} / \mathrm{P}^{\mathrm{i}}$ for some price levels $\mathrm{P}^{\mathrm{j}}, \mathrm{j}=1, \ldots, \mathrm{J}$, and rewrite the multilateral quantity indexes $Q^{i j}$ as $Q^{i j}=Q^{i} / Q^{i}$ for some quantity levels $Q^{j}, j=1$, ..., J. We now assume that the price and quantity levels satisfy the following adding up conditions:

$$
P^{j} Q^{j}=p^{j} \cdot q^{j}, j=1, \ldots, J \text {. }
$$

The economic statistician now picks the "best" bilateral price and quantity indexes, $P\left(p^{i}, p^{j}, q^{i}, q^{j}\right)$ and $Q\left(p^{i}, p^{j}, q^{i}, q^{j}\right)$, that satisfy the product test (1). Country price levels $P^{j}$ may now be found by solving the following least squares problem:

$$
\begin{aligned}
& \min _{p 1} \ldots, p^{J} \Sigma_{i=1}^{J} \Sigma_{j=1}^{J}\left\{\ln \left[\left(P^{i} / P^{j}\right) P\left(p^{i}, p^{j}, q^{i}, q^{j}\right)\right]\right\}^{2} \\
& =\min _{p^{1}, \ldots, p^{J}} \Sigma_{i=1}^{j} \Sigma_{j=1}^{j}\left\{\ln \left[\left(P^{i} / P^{j}\right) p^{j} \cdot q^{j} / p^{i} \cdot q^{i} Q\left(p^{i}, p^{j}, q^{i}, q^{j}\right)\right]\right\}^{2} \quad \text { using (1) }
\end{aligned}
$$

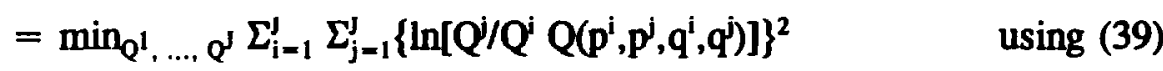

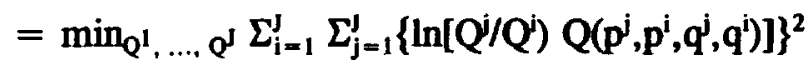

where (40) follows from the line above if $Q$ satisfies the time reversal test. In order to solve (39), a normalization on the $\mathrm{P}^{\mathrm{j}}$ (such as $\mathrm{P}^{1}=1$ ) is required and in order to solve (40), a normalization on the $Q^{j}$ (such as $Q^{1}=p^{1} \cdot q^{1}$ ) is required. If the $P^{j}$ are determined by solving (39), then the corresponding $Q^{j}$ can be obtained by solving (38). If the $Q^{j}$ are determined by solving (40), then the corresponding $\mathrm{P}^{\mathrm{j}}$ can be obtained by solving (38). The equality between (39) and (40) shows that if the bilateral price or quantity index satisfies the time reversal test, then it does not matter whether we solve a least squares problem involving the $\mathrm{P}^{j}$ or an analogous problem involving the $Q^{\mathrm{i}}$ : the same system of price and quantity levels will be obtained which satisfy the product test relations (38). Eltetö and Köves [1964] and Szulc [1964] used the least squares problem (39) with the bilateral formula $P$ chosen to be the Fisher ideal $P_{F}$ defined by (13) to derive the EKS purchasing power parities Pj. Van Ijzeren [1987; 62-65] showed that one also obtained the Gini-EKS parities if either $P_{F}, P_{L}$ or $P_{P}$ (recall (13), (2) and (3) above) were used as the bilateral index number formula $P$ in 
(39) or if $Q_{F}, Q_{L}$ or $Q_{P}$ (recall (14), (5) and (4) above) were used as the bilateral index number formula Q in (40). Hill [1993; 396] concluded his discussion of the EKS multilateral system by observing that the EKS quantity levels $Q^{j}$ are not additively consistent across commodities.

Hill [1993; 397] concluded his discussion of multilateral indexes by recommending that Statistical Agencies compile both Geary-Khamis indexes (because they are additively consistent) as well as Gini-EKS indexes because they are based on bilateral Fisher ideal indexes which have a better justification from the viewpoint of economic theory (recall our discussion of superlative indexes in section 3 above).

In the context of bilateral index number theory, we saw that the requirement that a quantity index be additive in its quantity components was not inconsistent with the index being superlative if we were making comparisons over only two periods. Unfortunately, in the multilateral context, if there are more than 3 countries in the block, then it appears to be impossible to achieve both additivity and superlativeness. Let me try to explain why this is so.

Assume optimizing behavior on the part of economic agents in each country; i.e., assume consumers in country $i$ are maximizing a nonnegative, linearly homogeneous, increasing and concave utility function $f(q)$ subject to the country $i$ budget constraint, $p^{i} \cdot q=p^{i} \cdot q^{i}$ for $i=1,2, \ldots, J .{ }^{29}$ We shall assume strictly positive prices and quantities in all countries to simplify our proofs. The assumption of optimizing behavior plus the linear homogeneity of the aggregator function $f$ implies that

$$
p^{i} \cdot q^{i}=c\left(p^{i}\right) f\left(q^{i}\right), \quad i=1,2, \ldots, J,
$$

where $c(p)$ is the unit cost function dual to the aggregator function $f$; i.e., $c(p) \equiv C(1, p)$ where the (total) cost function $C$ was defined earlier by (9). Finally, we introduce the notation $e_{i}$ and $u_{i}$ for country i's unit cost and utility level respectively; i.e., define:

$$
\begin{aligned}
& u_{i} \equiv f\left(q^{i}\right), i=1, \ldots, J \\
& e_{i} \equiv c\left(p^{i}\right), i=1, \ldots, J
\end{aligned}
$$


If the unit cost function $c$ is differentiable, then by Shephard's $[1953 ; 11]$ Lemma $^{30}$, we can obtain quantities $q^{i}$ as functions of the prices $p^{i}$ and utility levels $u_{i}$ as follows:

$$
\mathrm{q}^{\mathrm{i}}=\operatorname{vc}\left(\mathrm{p}^{\mathrm{i}}\right) \mathrm{u}_{\mathrm{i}}, \mathrm{i}=1, \ldots, \mathrm{J}
$$

where $\pi c\left(p^{i}\right) \equiv\left[c_{1}\left(p^{i}\right), \ldots, c_{N}\left(p^{i}\right)\right]$ is the vector of first order partial derivatives of $c\left(p^{i}\right)$ with respect to its price components.

If the aggregator function $f$ is differentiable, then we can obtain prices $p^{i}$ as functions of the quantities $q^{i}$ and the unit cost levels $e_{i}$ as follows: ${ }^{31}$

$$
p^{i}=\nabla f\left(q^{i}\right) e_{i}, i=1, \ldots, J .
$$

We now want to determine under what conditions on $f$ or $c$, the additive quantity index defined by (30) is exactly equal to the economic index, $f\left(q^{j}\right) / f\left(q^{j}\right)=u_{j} / u_{i}$, for all $i$ and $j$. In order to allow for more general average prices $\bar{p}_{n}$ other than those defined by (31) and (32), we replace $\bar{p}_{n}$ by $m\left(p_{n}^{1}, p_{n}^{2}, \ldots, p_{n}^{J}\right)$ for $n=1,2, \ldots, N$ where $m$ is a homogeneous symmetric mean. ${ }^{32}$

Equating the right hand side of $(30)$ to the aggregate quantity ratio $f\left(q^{j}\right) / f\left(q^{i}\right)$ and replacing each $\bar{p}_{n}$ by the general mean $m\left(p_{n}^{1}, \ldots, p_{n}^{J}\right)$ of the country prices for commodity $n$ leads to the following system of functional equations that $f$ or $c$ must satisfy for all prices and quantities $p^{1}, \ldots$, $p^{\prime}$ and $q^{1}, \ldots, q^{J}$ that satisfy (41)-(45):

$$
\Sigma_{n=1}^{N} m\left(p_{n}^{1}, \ldots, p_{n}^{J}\right) q_{n}^{j} / \Sigma_{n=1}^{N} m\left(p_{n}^{1}, \ldots, p_{n}^{J}\right) q_{n}^{i}=f\left(q^{j}\right) / f\left(q^{i}\right), 1 \leq i, j \leq J .
$$

We first consider the case where the unit cost function $c$ is once differentiable. In this case, we can eliminate the $q^{i}$ in (46) by substituting (42) and (44) into (46). Defining $c_{n}\left(p_{1}, \ldots, p_{N}\right)=$ $\delta c_{n}\left(p_{1}, \ldots, p_{N}\right) / \delta p_{n}$ and after simplifying, the resulting equations are:

$$
\Sigma_{n=1}^{N} m\left(p_{n}^{1}, \ldots, p_{n}^{J}\right)\left[c_{n}\left(p^{j}\right)-c_{n}\left(p^{i}\right)\right]=0 ; 1 \leq i, j \leq J .
$$

Fix $i$ and $j$. If $\mathbf{N} \geq 3$, there exists a country $k$ not equal to $i$ or $j$. Choose a set of $\mathbf{N} p^{k}$ vectors, say $\mathrm{p}^{\mathrm{kr}}$ for $\mathrm{r}=1, \ldots, \mathrm{N}$, such that the $\mathrm{N}$ vectors, $\left[\mathrm{m}\left(\mathrm{p}_{1}^{1}, \ldots, p_{1}^{k r}, \ldots, \mathrm{p}_{1}^{\mathrm{J}}\right), \mathrm{m}\left(\mathrm{p}_{2}^{1}, \ldots, p_{2}^{k r}\right.\right.$, $\left.\left.\ldots, \mathrm{p}_{2}^{\mathrm{J}}\right), \ldots, \mathrm{m}\left(\mathrm{p}_{\mathrm{N}}^{1}, \ldots, p_{N}^{k r}, \ldots, \mathrm{p}_{N}^{\mathrm{J}}\right)\right]$ for $\mathrm{r}=1, \ldots, \mathrm{N}$, are linearly independent. ${ }^{33}$ Inserting the prices $\left[p^{1}, \ldots, p^{k r}, \ldots, p^{j}\right]$ for $r=1, \ldots, N$ into $(47)$ in place of $\left[p^{1}, \ldots, p^{k}, \ldots, p^{j}\right]$ leads to $N$ 
linearly independent equations in the variables $\left[c_{n}\left(p^{j}\right)-c_{n}\left(p^{i}\right)\right]$ and hence we conclude that

$c_{n}\left(p^{j}\right)-c_{n}\left(p^{i}\right)=0$ for $n=1, \ldots, N$ and $1 \leq i, j \leq J$.

Equations (48) imply that the first order partial derivatives of $c(p)$ are constants, $b_{n}$ say, and thus $c(p)$ must be the following linear function of prices: ${ }^{34}$

$c\left(p_{1}, \ldots, p_{N}\right)=\Sigma_{n=1}^{N} b_{n} p_{n}$

Equation (49) tells us that the unit cost function is the Leontief unit cost function which is dual to the zero substitutability Leontief aggregator function $f\left(q_{1}, \ldots, q_{N}\right)=\min _{n}\left\{q_{n} / b_{n}: n=1, \ldots\right.$, N\}.

We now consider the case where the aggregator function $f$ is once differentiable. In this case, we can eliminate the $p^{i}$ in (46) by using equations (45). After simplifying, equations (46) become:

$\Sigma_{n=1}^{N} m\left[e_{1} f_{n}\left(q^{i}\right), \ldots, e_{J} f_{n}\left(q^{J}\right)\right]\left[\left\{q_{n}^{j} / f\left(q^{j}\right)\right\}-\left\{q_{n}^{i} / f\left(q^{i}\right)\right\}\right]=0,1 \leq i, j \leq J$

Let $\mathrm{f}$ be a linear aggregator function; i.e., suppose that there exist constants $\mathrm{a}_{\mathrm{n}}$ such that

$f\left(q_{1}, \ldots, q_{N}\right) \equiv \Sigma_{n=1}^{N} a_{n} q_{n}$

Substituting the partial derivatives of the f defined by (51) into the left hand side of (50) yields

$$
\begin{aligned}
& \sum_{n=1}^{N} m\left[e_{1} a_{n}, \ldots, e_{j} a_{n}\right]\left[\left\{q_{n}^{j} / f\left(q^{j}\right)\right\}-\left\{q_{n}^{i} / f\left(q^{i}\right)\right\}\right] \\
& \quad=\Sigma_{n=1}^{N} a_{n} m\left[e_{1}, \ldots, e_{j}\right]\left[\left\{q_{n}^{j} / f\left(q^{j}\right)\right\}-\left\{q_{n}^{i} / f\left(q^{i}\right)\right\}\right]
\end{aligned}
$$

using the linear homogeneity property of $\mathrm{m}$

$$
=m\left[e_{1}, \ldots, e_{\jmath}\right]\left[\left\{f\left(q^{j}\right) / f\left(q^{j}\right)\right\}-\left\{f\left(q^{i}\right) / f\left(q^{i}\right)\right\}\right]
$$

using (51) twice

$$
=0 \text {. }
$$

Thus if the aggregator function $f$ is linear, then the functional equation (50) is satisfied. We now show that if $J \geq 3$, then (51) is the only differentiable linearly homogenous aggregator function that satisfies $(50) .{ }^{35}$ 
Suppose that $f$ satisfies (50) and the first order partial derivatives of $f$ are not all constant. Then we can find two quantity vectors, $q^{(1)}$ and $q^{(2)}$ say, such that for some commodities $r$ and $s$, we have:

$$
\begin{aligned}
& \mathrm{f}_{\mathrm{r}}\left(\mathrm{q}^{(1)}\right)<\mathrm{f}_{\mathrm{r}}\left(\mathrm{q}^{(2)}\right) \\
& \mathrm{f}_{\mathrm{s}}\left(\mathrm{q}^{(1)}\right) \geq \mathrm{f}_{\mathrm{s}}\left(\mathrm{q}^{(2)}\right)
\end{aligned}
$$

Fix $i \neq j$ and choose $q_{n}^{i}=q_{n}^{j}$ for all $n$ except when $n=r$ or s. For these two components, choose $q_{r}^{i}, q_{s}^{i}, q_{r}^{j}, q_{s}^{j}$ such that $f\left(q^{i}\right)=f\left(q^{j}\right)$ and

$$
\left\{q^{j} / f\left(q^{j}\right)\right\}-\left\{q^{i} / f\left(q^{i}\right)\right\}=z_{r}>0
$$

$$
\left\{q_{s}^{j} / f\left(q^{j}\right)\right\}-\left\{q_{s}^{i} / f\left(q^{i}\right)\right\} \equiv z_{s} \leq 0
$$

Substitute these choices for $q^{i}$ and $q^{j}$ into (50) to obtain:

$$
m\left[e_{1} f_{r}\left(q^{1}\right), \ldots, e_{k} f_{r}\left(q^{k}\right), \ldots, e_{s} f_{r}\left(q^{J}\right)\right] z_{r}+m\left[e_{1} f_{s}\left(q^{l}\right), \ldots, e_{k} f_{s}\left(q^{k}\right), \ldots, e_{s} f_{s}\left(q^{J}\right)\right] z_{s}=0
$$

Since $J \geq 3$, there exists a country $k$ not equal to $i$ or $j$. Now replace $q^{k}$ in (56) by $q^{(1)}$ and then $q^{(2)}$. Rewrite the resulting two equations as:

$$
x_{11} z_{r}+x_{12} z_{s}=0 ; x_{21} z_{r}+x_{22} z_{s}=0
$$

The inequalities (52) and (53) plus the assumption that $\mathrm{m}$ is increasing in its arguments imply that the two equations in (57) are linearly independent. Hence the only solution is $z_{r}=z_{\mathbf{z}}=0$, which contradicts (54) and (55). Hence our supposition is false and we conclude that the linear aggregator function defined by (51) is the only differentiable linearly homogeneous function that can be exact for additive indexes of the form defined by the left hand side of (46).

Putting this result together with our earlier unit cost function result, we see that essentially the only functional forms for an underlying homogeneous aggregator function that are exact for additive quantity indexes of the type defined by the left hand side of (46) are the zero substitutability Leontief aggregator and the perfect substitutability linear aggregator functions. Thus although additivity may be very convenient for users, its economic foundations are rather weak. ${ }^{36}$

The economic foundations for the average quantities approach can be shown to be similarly 
weak. Allow the average quantities $\bar{q}_{n}$ which appear in (35) to be homogeneous symmetric means of the country quantities for commodity n; i.e., assume

$$
\bar{q}_{n}=m\left(q_{n}^{1}, \ldots, q_{n}^{J}\right), n=1, \ldots, N \text {. }
$$

Now equate the right hand side of (35) to the correct theoretical economic price index $c\left(p^{j}\right) / c\left(p^{i}\right)$. The counterparts to equations (46) now become:

$$
\Sigma_{n=1}^{N} m\left(q_{n}^{1}, \ldots, q_{n}^{J}\right) p_{n}^{j} / \Sigma_{n=1}^{N} m\left(q_{n}^{1}, \ldots, q_{n}^{J}\right) p_{n}^{i}=c\left(p^{j}\right) / c\left(p^{i}\right), 1 \leq i, j \leq J .
$$

First consider the case where the unit cost function $c(p)$ is once differentiable. Eliminate the $\mathrm{q}^{\mathrm{i}}$ in (59) by using (44). After simplification, (59) becomes for $1 \leq \mathrm{i}, \mathrm{j} \leq \mathrm{J}$ :

$$
\Sigma_{n=1}^{N} m\left[u_{1} c\left(p^{j}\right), \ldots, u_{j} c\left(p^{j}\right)\right]\left[\left\{p_{n}^{j} / c\left(p^{j}\right)\right\}-\left\{p_{n}^{i} / c\left(p^{i}\right)\right\}\right]=0
$$

which is exactly analogous to (50). Applying the previous analysis, we conclude that the unit cost function must be linear; i.e., (49) is the only differentiable unit cost function solution to (59) if $\mathrm{J} \geq$ 3.

Consider next the case where the aggregator function $\mathrm{f}$ is once differentiable. Eliminate the $\mathrm{p}^{\mathrm{i}}$ in (59) by substituting in equations (45). Using also (43), (59) becomes

$$
\Sigma_{n=1}^{N} m\left(q_{n}^{1}, \ldots, q_{n}^{J}\right)\left[f_{n}\left(q^{j}\right)-f_{n}\left(q^{j}\right)\right]=0,1 \leq i, j \leq J,
$$

which is exactly analogous to (47). Applying our previous analysis, we conclude that the aggregator function must be linear in this case.

Consolidating the above results, we see that the only functional forms for an underlying unit cost function that are consistent with the additive price indexes defined by the left hand side of (59) are the unit cost functions that are dual to the linear and Leontief aggregator functions.

The above results on the exactness of the average prices and average quantities methods for making multilateral comparisons can be generalized to more complex formulae for the average prices $m\left(p_{n}^{1}, \ldots, p_{n}^{J}\right)$ which appear in (46) or for the average quantitities $m\left(q_{n}^{1}, \ldots, q_{n}^{J}\right)$ which appear in (59). In particular, under conditions which guarantee the existence and uniqueness of the Geary-Khamis indexes, it can be shown that the linear and Leontief aggregator functions are the only functions 
which are exact for the Geary-Khamis parities.

Recently, Dikhanov [1994] has revisited the problem of obtaining additive quantity indexes in the multilateral context. Dikhanov noticed that the Ikle $[1972 ; 203]$ method for making multilateral comparisons is an average prices method which is analogous to the Geary-Khamis method $^{37}$ except that the average price for commodity $n$ is defined as follows:

$$
\bar{p}_{n} \equiv\left[\Sigma_{j=1}^{J}\left(\delta_{n}^{j} / \Sigma_{k=1}^{J} \delta_{n}^{i}\right)\left(p_{n}^{j} / P^{j}\right)^{-1}\right]^{-1}, n=1, \ldots, N
$$

where $\delta_{n}^{j} \equiv p_{n}^{j} q_{n}^{j} / p^{j} \cdot q^{j}$ is the expenditure share of commodity $n$ in country $j$ and $p^{j}$ is the country $j$ purchasing power parity defined by (14). Thus as in the GK system, the $\overline{\mathrm{p}}_{\mathrm{n}}$ and $\mathrm{P}^{\mathrm{j}}$ are determined simultaneously by (34) and (62). ${ }^{38}$ Note that the Iklé $\overline{\mathbf{p}}_{\mathrm{n}}$ is a weighted harmonic mean of the country j PPP adjusted prices of commodity $n, p_{n}^{j} / P^{j}$, where the (normalized) country $j$ expenditure shares for commodity $n, \delta_{n}^{j}$, are used as weights. The reader should compare the Iklé $\bar{p}_{n}$ defined by (62) with the Geary-Khamis $\overline{\mathrm{p}}_{\mathrm{n}}$ defined earlier by (33). The interesting property of the Ikle multilateral system of indexes is that their quantity levels $Q^{j}$ are additive over commodity components and Dikhanov [1994] shows using World Bank data that the Ikle $Q^{j}$ are numerically fairly close to the Gini-EKS Q'.

It is straightforward to show that the linear and Leontief aggregator functions are exact for the Iklé system of indexes. I suspect that these are the only aggregator functional forms that are exact, hut due to the complexity of (62), I have not been able to formally prove this.

In general, I am skeptical that additive multilateral quantity indexes of the type defined by (30) will be exact for flexible functional forms for the aggregator function if the number of countries (or time periods) exceeds two. This position seems to be in general agreement with that of Van Ijzeren as the following quotation indicates:

"Instead of additivity, another central idea has to be accepted, namely, that every subaggregate, just like every individual product, should have a complete set of prices and quantities. To get some value for a subaggregate it is not sufficient to add the corresponding values of its component products. On the contrary, a set of consistent prices and quantities should be constructed for the subaggregate, thus making it, 
formally, [equivalent] to a novel, solitary product."

Van Ijzeren [1987; 91-92]

We conclude this section with a few more references to the literature. Economic approaches to multilateral indexes have been considered by Caves, Christensen and Diewert [1982a] [1982b] and Diewert [1986]. Test approaches to multilateral indexes have been considered by Gerardi [1982], Hill [1982], Kravis, Summers and Heston [1982], Diewert [1986] [1988], and Balk [1993]. Other important works on multilateral methods not yet mentioned include Van Yzeren (Ijzeren) [1956] [1988], Drechsler [1973], Kravis [1984], Szilágyi [1986], Eurostat [1988], Summers and Heston [1988] [1991], Balk [1989] and Robert Hill [1994b]. The early history of multilateral methods is reviewed by Diewert [1993a; 52-58].

\section{The Treatment of Differences and Changes in Quality}

Hill [1993; 397-398] opened up his discussion of quality differences by discussing alternative criteria for classifying or distinguishing commodities. Commodities can be different due to: (i) differences in the physical characteristics of the good or differences in the delivery of services; (ii) different conditions of sale; i.e. inclusion or exclusion of transportation costs or warranties; different levels of customer service or different environments where sales take place (e.g., fancy versus plain restaurants); (iii) different locations or outlets where sales take place; and (iv) different times of the day or season when sales are made.

Differences (i) and (ii) listed above are relatively uncontroversial. The differences in (iii) mean that commodities should be distinguished by region and thus the national accounts of a country should in principle be constructed on a regional basis rather than on a national basis. Taking a national basis means that commodities that are homogeneous on the basis of physical and economic characteristics (recall (i) and (ii) above) could be aggregated together at the lowest level of aggregation. Taking a regional basis would mean that the same physical commodity produced in different locations would be treated as separate outputs in the system of national accounts (which 
is the correct treatment). However, it is not clear whether commodities should be distinguished not only by their region or market area, but also by their establishment or outlet (or point of sale or purchase). If commodities are distinguished by outlet, then shifts in purchases by consumers from high priced outlets to discount outlets will not show up as price declines in the national accounts.

With respect to classification criterion (iv), Hill was quite explicit in recommending that "peak load" or "time of day" commodities should be distinguished as separate commodities as should "seasonal" commodities:

"For example, electricity or transport provided at peak times must be treated as being of higher quality than the same amount of electricity or transport provided at off-peak times. The fact that peaks exist shows that purchasers or users attach greater utility to the services at these times, while the marginal costs of production are usually higher at peak times. The different prices or rates charged at peak and off-peak times provide measures of these differences in quality. Similarly, fruit and vegetables supplied out of season must be treated as higher qualities than the same fruit and vegetables in season which are cheaper to produce and of which consumers may be satiated."

Hill [1993; 398]

In the context of quarterly national accounts, Hill's proposed treatment of time of day commodities does not pose any conceptual problems: instead of being a homogeneous single commodity, say electricity consumption by an economic unit over a quarter, we simply disaggregate the consumption into peak and off peak components, with separate prices and quantities for each component. However, the treatment of seasonal commodities in sub annual accounts is much more difficult from a conceptual point of view. If we are constructing annual accounts, then following Hill's advice, we can disaggregate the annual transactions involving a seasonal commodity into price and quantity components distinguished by season. Then annual price and volume indexes can be constructed in the usual fashion, treating transactions for the commodity that take place in different seasons as separate commodities. Thus seasonal sales in the month of December will be compared with sales in the December of the base year. This is Stone's $[1956 ; 75]$ solution to the treatment of seasonal commodities in the context of annual accounts. However, when constructing quarterly or monthly accounts, this strategy breaks down. ${ }^{39}$ Hill did not offer any advice on what to do in this situation. 
Hill [1993; 398] made some very perceptive comments on the interpretation of price differences between commodities that are physically identical or very similar:

"In economic theory it is generally assumed that whenever a difference in price is found between two goods and services which appear to be physically identical there must be some other factor, such as location, timing, conditions of sale, etc., which is introducing a difference in quality. Otherwise, it can be argued that the difference could not persist, as rational purchasers would always buy lower priced items and no sales would take place at higher prices. In most cases, therefore, differences in prices at the same moment of time must be taken as prima facie evidence that the goods or services concerned represent different qualities of the same general kind of good or service."

Hill [1993; 398]

Hill noted that an implication of the above traditional view of price differences is that a shift towards higher priced varieties of the same physical commodity will lead to an increase in aggregate quantity rather than price; conversely, a shift towards lower priced varieties will lead to a decrease in aggregate quantity. If high and low prices remain the same in the two periods under consideration, then the above traditional view of price differences will imply no change in aggregate price no matter what shifts in demand occur. However, Hill went on to question the assumption that the existence of different prices during the same time period always reflects differences in the qualities of the goods or services sold:

"Nevertheless, it must be questioned whether the existence of observed price differences always implies corresponding differences in quality. There are strong assumptions underlying the standard argument which are seldom made explicit and are often not satisfied in practice: for example, that purchasers are well informed and that they are free to choose between goods and services offered at different prices."

Hill [1993; 398]

Hill [1993; 398-399] observed that the traditional view of price differences reflecting quality differences could be wrong for 3 reasons: (i) consumers may lack information on where the lowest price is to be found; i.e., they may have to search for the lowest price and search is costly; ${ }^{40}$ (ii) price discrimination may exist, particularly for government supplied goods and (iii) rationing of commodities sold at below normal prices may occur; put another way, many firms have "sales." 
The importance of Hill's discussion on the traditional view of price differences reflecting quality differences will become evident when Hill discusses methods for dealing with quality changes.

Another preliminary topic that Hill discussed very ably is the problem of price variation within the period for a homogeneous commodity; i.e., the sales of a particular commodity at a particular outlet over the accounting period of time will typically not take place at the same price. However, bilateral index number theory requires that all of this micro variation in prices and quantities during a period be aggregated into single price and quantity measures that will be inputs into the appropriate index number formula. How should this micro aggregation be accomplished?

"When there is price variation for the same quality of good or service, the price relatives used for index number calculation should be defined as the ratio of the weighted average price of that good or service in the two periods, the weights being the relative quantities sold at each price. Suppose, for example, that a certain quantity of a particular good or service is sold at a lower price to a particular category of purchaser without any difference whatsoever in the nature of the good or service offered, location, timing or conditions of sale, or other factors. A subsequent decrease in the proportion sold at the lower price raises the average price paid by purchasers for quantities of a good or service whose quality is the same and remains unchanged, by assumption. It also raises the average price received by the seller without any change in quality. This must be recorded as a price and not a volume increase."

Hill [1993; 399]

Thus Hill recommended the use of the commodity's unit value and the total quantity transacted as the theoretically correct price and quantity numbers that summarize the individual transactions involving the commodity over the accounting period under consideration. This treatment of commodity aggregation at the lowest level dates back to Walsh [1901; 96] [1921a; 88] and Davies $[1924 ; 187][1932 ; 59] .^{41}$

The use of unit values as the theoretically "correct" prices at the lowest level of aggregation has some rather strong implications for current Statistical Agency practices: instead of collecting price quotations from establishments or outlets that pertain to a single point of time within the accounting period, ${ }^{42}$ the total value of transactions and the total quantities transacted by the 
establishment during the accounting period should be collected. As more firms electronically record data on their transactions and as the costs of storing and transmitting information fall, this unit value approach to pricing becomes more feasible.

Hill [1993; 399] noted that the above contrasting views on the significance of different prices for the "same" commodity lead to difficult problems of judgement for Statistical Agencies: if the price differences are "superficial" and do not really reflect differences in quality, then unit values should be constructed that aggregate over all transactions involving these superficially different commodities to get the "correct" measure of average price that would be inserted into an index number formula. On the other hand, if the price differences are "real," then the commodity transactions should be disaggregated into quality constant groups of transactions and be treated as separate goods. If there is doubt as to whether the price differences are superficial or real, then Hill [1993; 399] recommended that the Statistical Agency assume that the price differences reflect real quality differences.

After completing the above introduction, Hill $[1993 ; 399-401]$ went on to discuss four possible ways of incorporating quality change into price and quantity indexes: (i) ignore the fact that a new "package" for an old good has appeared and simply treat the new good as being equivalent to the old good; (ii) omit the new good in the price index in the period when the new good first appears; (iii) adjust the new good's price for the change in quality; i.e., use a hedonic regression procedure or (iv) use the method of overlapping price quotations. Hill [1993; 399] did not favor the use of alternatives (i) and (ii).

The overlapping price quotes method relies on the old and new variety being available on the market simultaneously for at least one period. For example, consider the following three period situation: (1) in period 0 , the price and quantity transacted of the old good are $p_{1}^{0}$ and $q_{1}^{0}$ respectively; (2) in period 1 , the price and quantity of the old good are $p_{1}^{1}$ and $q_{1}^{1}$ and the price and quantity of the new good are $p_{2}^{1}$ and $q_{2}^{1}$ respectively; (3) in period 2 , the old good has disappeared 
and the price and quantity transacted of the new good are $p_{2}^{2}$ and $q_{2}^{2}$. Treating period 0 as the base period, the overlapping price quotes method treats the period 1 price index for the commodity group as the old goods price ratio, $\mathrm{p}_{1}^{1} / \mathrm{p}_{\mathrm{l}}^{0}$. The price index going from period 1 to 2 is taken to be the new goods price ratio $\mathrm{p}_{2}^{2} / \mathrm{p}_{2}^{1}$. The overall sequence of price indexes for the three periods is assumed to be:

$$
1, p_{1}^{1} / p_{1}^{0},\left(p_{1}^{1} / p_{1}^{0}\right)\left(p_{2}^{2} / p_{2}^{1}\right)
$$

Dividing the above price indexes into the value ratios gives us the following sequence of quantity indexes for the overlapping quotes method:

$$
1,\left(q_{1}^{1} / q_{1}^{q}\right)+\left(p_{2}^{1} / p_{1}^{1}\right)\left(q_{2}^{1} / q_{1}^{q}\right),\left(p_{2}^{1} / p_{1}^{1}\right)\left(q_{2}^{2} / q_{1}^{q}\right) \text {. }
$$

Thus the overlapping price quotes method assumes that one unit of the new good is equivalent in terms of final use utility to $p_{2}^{1} / p_{1}^{1}$ units of the old good; i.e., this method relies heavily on the assumption that the observed prices of both varieties in period 1 reflect real quality differences. Note that the goods are assumed to be perfect substitutes using the linear conversion factor, $p_{2}^{1} / p_{1}^{1}$.

Let us now follow the example of Hill and assume that: (i) the new and old goods are denominated in the same effective final use units (e.g., when comparing a new computer with an old one that differs in only one characteristic, say "speed," we denominate the prices of the two computers in dollars per unit of speed) and (ii) the price differences in period 1 reflect only transitory differences and hence the correct price for the computer aggregate in period 1 is the unit value $\left[p_{1}^{1} q_{1}^{1}+p_{2}^{1} q_{2}^{1}\right] /\left[q_{1}^{1}+q_{2}^{1}\right]$. Under these assumptions, the correct sequence of price indexes for the three periods would be:

$$
1,\left(p_{1}^{1} / p_{1}^{q}\right)\left[q_{1}^{1} /\left(q_{1}^{1}+q_{2}^{1}\right)\right]+\left(p_{2}^{1} / p_{1}^{q}\right)\left[q_{2}^{1} /\left(q_{1}^{1}+q_{2}^{1}\right)\right], p_{2}^{2} / p_{1}^{0} .
$$

Typically, the old good will be overpriced compared to the new good when prices are measured in efficiency units; i.e., we will typically have $p_{1}^{1}>p_{2}^{1}$. Under these conditions, it can be verified that the period 1 and period 2 prices in the unit value sequence of prices (65) will be lower than the corresponding period 1 and 2 overlapping quotes prices in (63); i.e., under the above 
conditions, the traditional method will have an upward bias. ${ }^{43}$

We could take the point of view that is the opposite of the above unit value approach and assume that the new variety is a genuine new good that cannot be aggregated with the old good using a linear conversion factor as in (64). In this situation, we can apply the theoretical approach of Hicks $[1940 ; 114]$ and assume that there exists a period 0 reservation price, $p_{2}^{0 *}$, that would just equate demand for the new good to zero in period 0 . We also assume the existence of a period 2 reservation price, $p_{1}^{2 *}$, that equates demand for the disappearing old good equal to zero in period 2 . Unfortunately, these reservation prices are unobservable and hence econometric estimation to determine them must be undertaken ${ }^{44}$ or various conventional guesses for them must be made. ${ }^{45}$ We assume that the quantity of the new good in period 0 is zero $\left(q_{2}^{0} \equiv 0\right)$ and the quantity of the disappearing old good in period 2 is zero $\left(q_{1}^{2} \equiv 0\right)$. With these assumptions, we can evaluate the 3 period sequence of fixed base Laspeyres and Paasche price indexes, which turn out to be:

$$
\begin{array}{lll}
P_{L}\left(p^{0}, p^{1}, q^{0}, q^{1}\right)=1, & p_{1}^{1} / p_{1}^{0}, & p_{1}^{2 *} / p_{1}^{0} ; \\
P_{P}\left(p^{0}, p^{t}, q^{0}, q^{1}\right)=1,\left[p_{1}^{1} q_{1}^{1}+p_{2}^{1} q_{2}^{1}\right] /\left[p_{1}^{0} q_{1}^{1}+p_{2}^{0 *} q_{2}^{1}\right], p_{2}^{2} / p_{2}^{0 *} .
\end{array}
$$

For successful new varieties; i.e., varieties that cause the demand for the old varieties to decrease dramatically, we can conjecture that the period 0 reservation price for the new variety, $p_{2}^{0 *}$, is considerably higher than its period 1 price $p_{2}^{1}$, adjusted for inflation between periods 0 and 1 , using $\mathrm{p}_{1}^{0} / \mathrm{p}_{1}^{1}$ as the inflation adjustment. Thus for successful new varieties, we will normally have

$$
\mathrm{p}_{2}^{0 *}>\mathrm{p}_{2}^{1}\left(\mathrm{p}_{1}^{0} / \mathrm{p}_{1}^{1}\right)
$$

As for the disappearing variety, if we were to assume that the reservation price for good 1 in period 2 were simply its period 1 price $p_{1}^{1}$, adjusted for inflation between periods 1 and 2 using $\mathrm{p}_{2}^{2} / \mathrm{p}_{2}^{1}$ as the escalator, producers would probably be supplying the old good in period 2 . Since there is no demand for the old good in period 2, it is probable that the old good reservation price lies below $p_{1}^{1}\left(p_{2}^{2} / p_{2}^{1}\right)$; i.e., we will usually have

$$
\mathbf{p}_{1}^{2 *}<\mathbf{p}_{1}^{1}\left(\mathbf{p}_{2}^{2} / \mathbf{p}_{2}^{1}\right)
$$


If we substitute (69) into (66) and (68) into (67), we find that

$P_{L}\left(p^{0}, p^{2}, q^{0}, q^{2}\right)<\left(p_{1}^{1} / p_{1}^{0}\right)\left(p_{2}^{2} / p_{2}^{1}\right)$

$$
P_{p}\left(p^{0}, p^{2}, q^{0}, q^{2}\right)<\left(p_{1}^{1} / p_{1}^{0}\right)\left(p_{2}^{2} / p_{2}^{1}\right) \text {. }
$$

Thus under the above hypotheses, in period 2, both the fixed base Laspeyres and Paasche price indexes will be less than the corresponding price obtained by the traditional overlapping price method (recall the last entry in (63)).

The above analysis indicates that from both the unit value perspective and the new good perspective, the traditional overlapping price quotes method for dealing with quality change is likely to impart an upward bias to price indexes in many situations. With the growth in international trade and the proliferation of new products that has taken place over the past two decades, there is a need for Statistical Agencies to carefully examine their procedures for dealing with new products. ${ }^{46}$

The hedonic method for adjusting price indexes for changes in the quality of goods was introduced by Court [1939] in order to deal with situations where the new varieties involved changes in more than one important characteristic.

"Price per unit is a satisfactory procedure where the useful and desirable qualities of an article can be roughly summarized in terms of a single specification. Passenger cars serve so many diverse purposes that such a single, most important specification can not be found (like rated tonnage in the case of trucks). The simple method is inapplicable, but why not combine several specifications to form a single composite measure?

The Hedonic suggestions are addressed to this problem of establishing an objective measure of usefulness and desirability in terms of which prices of products of complex function can be compared. In the case of passenger cars, if the relative importance to the customer of horsepower, braking capacity, window area, seat width, tire size, etc., could be established, the data reflecting these characteristics could be combined into an index of usefulness and desirability. Prices per vehicle divided by this index of Hedonic content would yield valid comparisons in the face of changing specifications."

Court $[1939 ; 107]$

Court $[1939 ; 109-110]$ went on to set up essentially the modern hedonic regression framework: the logarithm of an auto price was regressed on a linear function of automobile characteristics (weight, wheelbase and horsepower) plus some time dummies (which were later converted into annual price 
indexes for autos).

Hill made the following observations on the applicability of the hedonic method:

"The hedonic hypothesis may be used for any goods or services whose prices depend mainly on a few basic characteristics and for which sufficient numbers of different models, or qualities, are on sale on the market at the same time."

Hill $[1993 ; 401]$

For a sampling of the vast literature on the hedonic approach to adjusting for quality change,

see Stone [1956; 47-60], Griliches [1961] [1971], Diewert [1980; 503-505], Triplett [1986] [1987] [1989], Dulberger [1989], Gordon [1989] [1990], Berndt [1991] and Berndt and Griliches [1993]. For general discussions of quality change issues, see Court [1939; 103-105], Hofsten [1952], Fisher and Shell [1972], Gordon [1990] [1992] and Baldwin, Després, Nakamura and Nakamura [1994].

\section{Choice Between Direct and Indirect Measurement of Prices and Volumes}

When comprehensive price and quantity data are both available, Hill $[1993 ; 401]$ noted that it is not necessary to calculate both the price and quantity indexes, since given one of the indexes, the product test, equation (1), can be used to generate the other index.

However, in a sampling context when complete price and quantity information is not available, Hill recommended that the price index be calculated directly (from the sample information) and the quantity index be calculated indirectly using (1), (assuming that the value ratio $p^{t} \cdot q^{t} / p^{0} \cdot q^{0}$ can be calculated using other non sample information). Hill gave two reasons for calculating the price index rather than the volume index from the sample information:

"There are two reasons for this: first, it is usually necessary to estimate the average price or volume change from a selection or sample, of goods and services, and price relatives tend to have a smaller variance than the corresponding quantity relatives. Thus, the sampling error for a price index tends to be smaller than for a volume index. Secondly, the volume changes associated with new and disappearing products are properly reflected when current values are deflated by price indices."

Hill [1993; 401] 
Hill's first reason for preferring to construct the price index directly rather than indirectly is certainly valid from an empirical point of view. ${ }^{47}$ However, we must be a bit cautious in accepting his second argument without some qualification. Hill esssentially advocated what Keynes [1930; 94] called the highest common factor method for dealing with the new goods problem: simply ignore any new or disappearing goods in the two time periods under consideration and calculate the price index on the basis of the goods that are common to the two situations. This is essentially equivalent to the overlapping price quotes method for dealing with new goods. As we saw in the previous section, this method is likely to impart an upward bias to the price index in many situations. ${ }^{48}$ Although it is not practical to ask Statistical Agencies to estimate reservation prices for new and disappearing goods, it seems practical to ask them to utilize the overlapping unit values method (65) if the new good differs from an existing good in only one important characteristic.

\section{Non-Market Goods and Services}

What should national income accountants do when there are no market prices for an output (or "unreasonable" market prices)? Hill [1993; 402] suggested the following strategy: (i) set the value of the output equal to the cost of producing it; (ii) calculate some sort of quantity indicator for the output. Now use (i) for values and (ii) for quantities, and prices can be calculated by dividing values by quantities. Once prices and quantities have been obtained, normal index number theory can be applied. This is a very sensible strategy and can be implemented with a bit of work. ${ }^{49}$

Hill [1993; 402-403] recommended that the "full" cost of production be used when calculating costs for government subsidized outputs and be included in this cost: (a) labour costs; (b) intermediate input costs; (c) depreciation of capital inputs and (d) input taxes, but there was no mention of interest cost, since interest is treated as a transfer in the System of National Accounts and not as a productive output. This treatment of interest seems to us to be incorrect. 
10. The Scope of Price and Volume Measures in the System

Hill [1993; 403] noted that his discussion of price and volume measures up to this point related mostly to the flows of goods and services provided by the production sector and utilized by the household sector. Hill further observed that some components of input cost could also be decomposed into price and volume components, including: (i) labour compensation; (ii) consumption of fixed capital (depreciation) and (iii) taxes and subsidies on products (values are total tax payments pertaining to the commodity and the corresponding prices are taxes paid per unit of the commodity). The remaining component of input cost is (iv) operating surplus. Hill did not recommend that operating surplus be decomposed into price and volume components.

"The net operating surplus is an accounting residual which does not possess quantity and price dimensions of its own. It may also be negative, of course. It is not possible, therefore, to decompose the net operating surplus into its own price and volume components."

Hill [1993; 403]

Here again we see a deficiency in the national income accounting framework due to the treatment of interest as being unproductive. If interest (including imputed interest on equity capital) were treated as a productive factor of production and user costs ${ }^{50}$ for the capital components of cost were calculated, then the interest and depreciation components of user cost would lead to a greatly diminished $^{51}$ "operating surplus." This diminished operating surplus would be approximately equal to the economist's notion of "pure profits" and would typically be very small. Hence the fact that pure profits could not be decomposed into price and quantity components would not matter very much due to their small size.

\section{Measures of Real Income for the Total Economy}

Hill [1993; 403-405] considered two substantive topics in this section: (i) how can the real income of an economy be defined and (ii) how can gross domestic product be adjusted for changes in the economy's terms of trade? 
On the first question, Hill did not make any specific recommendations. Typically, a consumer price index or a producer price index is used to deflate household nominal income into a "real" income. 52

On the second question, Hill $[1993 ; 404]$ noted that a rise in the price of a country's exports relative to the price of its imports has an effect that is similar to a productivity gain: the economy can provide domestic final demanders with more outputs for the same amounts of domestic inputs supplied to the production sector of the economy.

General references to the adjusting for changes in the terms of trade literature include Nicholson [1960], Bjerke [1968], Kurabayashi [1971], Hamada and Iwata [1984] and Silver and Mahdavy [1989]. For an approach which is more explicitly based on producer theory and exact index numbers, see Diewert [1983b; 1083-1100], Diewert and Morrison [1986] [1990] and Kohli [1990] [1993].

\section{Sources of Bias in Consumer Price Indexes}

It may be useful to alert national income accountants to the recent literature on sources of bias in consumer price indexes. Many of these sources of bias are also present in producer price indexes. Recent surveys on this topic include Gordon [1993], Fixler [1993], Crawford [1993], Wynne and Sigalla [1994] and Diewert [1995a].

Of course, bias can only be defined relative to the "correct" underlying theoretical concept. In what follows, the "correct" concept is taken to be the Konüs [1924] price index, generalized to groups of consumers. ${ }^{53}$

At least five sources of bias have been distinguished in the literature: (1) elementary price index bias; (ii) commodity substitution bias; (iii) outlet substitution bias; (iv) overlapping price quotes bias and (v) new goods bias.

Elementary price index bias results from the use of an inappropriate index number formula 
to aggregate up prices at the very lowest level of aggregation. This source of bias added approximately .5\% per year to the U.S. consumer price index for the years 1987-1994; see Moulton [1993], Reinsdorf and Moulton [1994] and Armknecht, Moulton and Stewart [1994]. Recent papers dealing with this type of bias include Szulc [1989], Dalén [1992], Balk [1994a], Schultz [1994] and Diewert [1995a].

Commodity substitution bias is the bias which results from the use of Laspeyres or Paasche price indexes, which are exact only for preferences that exhibit no substitution. ${ }^{54}$ This source of bias can be avoided by the use of superlative price indexes. The work of Manser and McDonald [1988], Balk [1990; 82] and Aizcorbe and Jackman [1993] indicates that this source of bias adds about .2 to $.3 \%$ per year to a typical consumer price index (CPI).

Outlet substitution bias is the bias which results from inappropriately treating purchases from high and low cost outlets as separate goods; recall Hill's discussion on the validity of regarding price differences as evidence of quality differences in section 7 above. The estimates of Reinsdorf [1993] and Saglio [1994] suggest that this bias might add something like $.25 \%$ to $.4 \%$ per year to a typical CPI in recent years.

Griliches [1979; 97] and Gordon [1981] [1990] [1993] emphasized the source of bias that results when the overlapping price quotes method of adjusting for quality change is used. ${ }^{55}$ Gordon [1990] estimated that the durables component of the U.S. CPI was biased upward by about $1.5 \%$ per year during the period 1947-1983 due to this source of bias.

Our final source of bias is the new goods bias which results from an expansion in consumers' choice sets. ${ }^{56}$ Hill $[1988 ; 138]$ explicitly recognized this source of bias in an earlier paper, but he did not suggest a method for dealing with the problem. Griliches $[1979 ; 97]$ and Gordon $[1981 ; 130]$ and Diewert [1987; 779] [1993a; 59-63], following Marshall's [1887; 373] analysis of product cycle pricing, suggested that this bias could be substantially reduced by simply introducing new goods into the pricing basket in a timely fashion. ${ }^{57}$ Triplett $[1993 ; 200]$ termed the subset of the new goods bias 
caused by delays in introducing new products into the index the new introductions bias. Empirical evidence on the possible magnitude of the new goods bias can be found in Berndt, Griliches and Rosett [1993], Griliches and Cockburn [1994] and Hausman [1994].

Of all the sources of bias listed above, I believe that the biases associated with the introduction of new goods are the most significant. In the past 15 years, we have seen a proliferation of new goods and services. Traditional economics, rooted in models which have only a fixed number of commodities, has, by and large, missed the significance of this phenomenon of an increasing dimension for the commodity space. ${ }^{58}$ Thus productivity improvements are no longer taking place only by production units achieving economies of scale, but also by the application of science and technology through the creation of new products and new processes. It seems likely that Statistical Agencies have simply missed the improvements in our standard of living that are due to the increased number of commodities that consumers now have in their choice sets.

\section{Omitted Topics}

A number of additional topics could be discussed in the context of constructing price and volume indexes. We list a few of them below:

(i) The current System of Accounts has no role for productivity accounts. ${ }^{59}$ The reason for this omission can be traced to the System's treatment of interest; recall our discussion of this topic in section 10 above.

(ii) The current System of Accounts has an inconsistent treatment of durables in consumer price and volume indexes: housing is treated appropriately as a flow of consumption services but for other consumer durables, only additions to household stocks count. Again, there is a reluctance on the part of national income accountants to embrace the user cost concept. In order to improve the international (and intertemporal) comparability of consumption and savings statistics, consumption flows should be modelled rather than additions to stocks. ${ }^{60}$ 
(iii) The reluctance of the System to impute a productive role for interest leads to rather strange measures of output for most financial industries as well as for distributive industries where inventory holdings are large. Again, a user cost approach would lead to straightforward measures of inputs and outputs. ${ }^{61}$

(iv) There are major conceptual problems involved in measuring the outputs of industries where risk or uncertainty is associated with the outputs sold; e.g., insurance, gambling and financial options. This is an area for future research. ${ }^{62}$

We conclude this section by providing a few references to the vast literature on seasonal adjustment (recall Hill's discussion of seasonal commodities in section 7 above). References that take primarily economic approaches to seasonal adjustment include Turvey [1979], Balk [1980a] [1980b], Diewert [1983c] and Baldwin [1985]. References that take primarily statistical approaches include Cleveland [1983], Bell and Hillmer [1984] and Hylleberg [1992].

\section{Conclusion}

Peter Hill has written a masterful survey of modern index number theory and practice. Chapter 16 of the System of National Accounts 1993 will be an invaluable reference for not only national accounting specialists but also for students and practitioners of economics in general. In 27 pages, Hill has managed to accurately summarize a vast literature in an elegant and readable fashion -- a splendid accomplishment! 


\section{FOOTNOTES}

"Professor of Economics at the University of British Columbia and Research Associate of the National Bureau of Economic Research. This research was supported by a Strategic Grant from the Social Sciences and Humanities Research Council of Canada. Discussions with Peter Hill and Jack Triplett were very helpful. Thanks are due as well to Alice Nakamura for editorial assistance and also to Louise Hebert and Keltie Stearman for typing a difficult manuscript.

1. Rather than use Hill's notation for prices and quantities which involved double subscripts, we use a more standard notation where the superscript denotes the time period and the subscript denotes the commodity. We change Hill's notation in other ways as well.

2. Define the inner product of the vectors $p^{t}$ and $q^{t}$ as $p^{l} \cdot q^{i} \equiv \Sigma_{i=1}^{N} p_{i}^{q} q_{j}^{q}$. Frisch [1930; 399] called (1) the product test while Samuelson and Swamy [1974; 572] called it the weak factor reversal test. The originator of the test was Irving Fisher [1911; 403].

3. This point was originally made by Bortkiewicz $[1923 ; 377]$.

4. Diewert $[1976 ; 115]$ introduced this term to cover both the consumer and production theory contexts.

5. This result seems to have been obtained first by Frisch [1936; 24]; for a modern proof, see Pollak $[1971 ; 65]$. Hill did not mention another result due to Konūs $[1924 ; 20-21]$ that does not require the assumption of homotheticity: there exists a utility level between $\mathbf{u}^{0}$ and $\mathbf{u}^{t}, \mathbf{u}^{*}$ say, such that $P_{K}\left(p^{0}, p^{t}, u^{*}\right)$ lies between $P_{L}$ and $P_{p}$; see Diewert [1981; 185] for a modern proof of this result.

6. Walsh [1921b] showed Fisher [1921] how to "rectify" any index number formula to make it consistent with the time reversal test, a fact which Fisher [1922] neglected to mention in his book.

7. Moreover, the product of the price and quantity indexes must equal the appropriate value ratio; i.e., (1) must be satisfied. Diewert [1992a] showed that the Fisher ideal indexes satisfy more 
sensible tests than any of the other bilateral indexes commonly used.

8. Christensen, Jorgenson and Lau [1973] introduced the translog functional form into the economics literature.

9. Diewert $[1976 ; 123-124]$ also showed that $Q_{T}$ is exact for a general nonhomothetic aggregator function provided that the Malmquist [1953] quantity index is used as the underlying theoretical construct.

10. This problem was stressed by Turvey $[1989 ; 1]$. It was also mentioned by Arthur Bowley in his response to Fisher $[1923 ; 252]$ as the following quotation indicates: "The trouble is that we only infrequently have the data for double weighting, and it is therefore important to examine carefully the criticisms and tests applied to formulae in actual use."

11. Diewert and Wales [1987; 54] established the flexibility of this functional form.

12. Sidgwick $[1883 ; 68]$ and Bowley $[1901 ; 227]$ first proposed the use of $(23)$ applied to price indexes; Fisher [1922; 487] listed the price index counterparts to (23) and (24) as his formulae 8053 and 8054.

13. Walsh [1921a; 108] called his test the circular test while Diewert [1993a; 40] called it a multiperiod identity test. Fisher [1922; 64] specialized Walsh's test to two periods and called it the time reversal test.

14. The indexes defined by (23) and (24) also satisfy the time reversal test in the sense that $Q_{q^{0}}\left(p^{0}, p^{i}, q^{0}, q^{t}\right) Q_{q^{0}}\left(p^{i}, p^{0}, q^{i}, q^{0}\right)=1$ and $Q_{q^{1}}\left(p^{0}, p^{t}, q^{0}, q^{0}\right) Q_{q^{1}}\left(p^{t}, p^{0}, q^{l}, q^{0}\right)=1$.

15. However, if we treat $\alpha$ as a fixed quantity vector $q$, then $Q_{a}\left(p^{0}, p^{t}, q^{0}, q^{t}\right)=\left[\left(p^{t} \cdot q^{t} / p^{t} q\right)+\right.$ $\left.\left(p^{0} \cdot q^{i} / p^{0} \cdot q\right)\right] /\left[\left(p^{i} \cdot q^{0} / p^{i} \cdot q\right)+\left(p^{0} \cdot q^{0} / p^{0} \cdot q\right)\right]=\Sigma_{n=1}^{N}\left[s_{n}^{0 *}+s_{n}^{i *}\right]\left[q_{n}^{i} / q_{n}\right] / \Sigma_{i=1}^{N}\left[s_{i}^{0 *}+s_{i}^{t *}\right]\left[q_{i}^{0} / q_{i}\right]$ where $s_{i}^{0 *} \equiv p_{i}^{0} q_{i} / p^{0} \cdot q$ and $s_{i}^{* *} \equiv p_{i}^{i} q_{i} / p^{i} \cdot q$ for $i=1, \ldots, N$. Thus when $\alpha=q$, the numerator of $Q_{\alpha}$ can be rewritten as a share weighted sum of the quantity relatives $q_{i}^{1} / q_{i}$ and the denominator as a share weighted sum of the quantity relatives $q_{i}^{0} / q_{i}$.

16. See Diewert $[1978 ; 888][1992 b ; 577-578]$. 
17. A symmetric mean of two numbers $x$ and $y, m(x, y)$ say, has at least the following two properties: (i) it is symmetric; i.e., $m(x, y)=m(y, x)$ and (ii) it has the mean property; i.e., $m(x, x)=x$. For further properties of symmetric means, see Diewert [1993b].

18. Samuetson and Swamy $[1974 ; 582]$ have a related result.

19. This section is based on Hill [1988; 135-145].

20. The chain principle was introduced independently into the economics literature by Lehr [1885; 45-46] and Marshall [1887; 373]. Both authors observed that the chain system would mitigate the difficulties due to the introduction of new commodities into the economy, a point also mentioned by Hill [1993; 388]. Fisher [1911; 203] introduced the term "chain system."

21. If the $\mathrm{p}^{\mathrm{t}}$ are approximately proportional to the base period price vector $\mathrm{p}^{0}$, there will be no major problems with the use of (5). However, in recent years, computers have become a large component of investment expenditures and their prices have been dropping dramatically year after year; see Dulberger [1989] and Triplett [1989] [1993]. As Young [1992; 33] notes: "changes in the prices and quantities of computers have been large enough to make the measurement of the change in real GDP quite sensitive to the choice of price weights." Thus the U.S. has given up on providing constant price indexes for the components of GDP back to 1926.

22. These points were made earlier by Diewert [1978; 895].

23. This point emerged from discussions with Jack Triplett.

24. If $\mathrm{Q}_{\alpha}$ were to be used, there is the awkward problem of choosing $\alpha$.

25. Initially, Hill [1993; 390-391] assumed that the dimensionality of the commodity space was $2 \mathrm{~N}$; i.e., each commodity was allowed to be either an input or output or both. He also initially assumed that the price vector for outputs was equal to the price vector for intermediate inputs. Hill [1993; 392] later recognized that at the economy wide level, changes in the volume of GDP may be calculated using data on total final expenditures and imports; i.e., at the total economy 
level, intermediate inputs become imports and hence will have different prices than the components of final demand. Note that this treatment of imports assumes that they flow through the producer sector of an economy initially, a treatment pioneered by Kohli [1978] [1991].

26. "It is as though a volume comparison were to be made between a complete decade and a single year." Hill [1993; 392].

27. Actually counterparts to the chain principle can be found in the multilateral context. Gerardi [1982; 399] and Robert Hill [1994a] suggested the use of multilateral chain systems where the links would be forged by minimizing some distance function depending on the prices and quantities of the two countries in that link. Hill suggested $\ln \left[\max \left\{P_{L}^{i j}, P_{p}^{i}\right\} / \min \left\{P_{L}^{i}, P_{p}^{i j}\right\}\right]$ (where $P_{L}^{i j}$ and $P_{P}^{i j}$ are the Laspeyres and Paasche price indexes between countries $i$ and $j$ ) as a suitable distance measure. For other distance functions, see Allen and Diewert $[1981 ; 433]$ and Martini [1992; 369]. Fisher [1922; 272] in his discussion of comparisons between Egypt, Georgia and Norway explicitly ruled out the use of a multilateral chain principle as the following quotation indicates: "But evidently, if we are intent on getting the very best comparison between Norway and Egypt, we should not go to Georgia for our weights."

28. Turvey [1989; ch. 3] defined the elementary level as the lowest level of aggregation.

29. Alternatively, assume that producers in country $i$ are maximizing revenue $p^{i \cdot} q$ subject to a nonnegative, linearly homogeneous, increasing and convex factor requirements function $f(q)=$ $u_{i}$ where $u_{i}>0$ is the quantity of input available. See Diewert [1974] for the duality between factor requirements functions and revenue functions.

30. See also Diewert [1993c; 117].

31. To derive this, use Wold's [1944; 69-71] Identity plus the linear homogeneity of $f$ which implies $q^{i} \cdot \nabla f\left(q^{i}\right)=f\left(q^{i}\right)=u_{i}$. See Diewert $[1993 c ; 135]$.

32. Diewert $[1993 b ; 361]$ defined a symmetric mean $m\left(x_{1}, \ldots, x_{N}\right)$ to be a continuous, symmetric and increasing function of its arguments which has the mean value property: $m(\lambda, \ldots, \lambda)=\lambda$ 
for all $\lambda$ in the domain of definition. For a homogeneous symmetric mean, add the linear homogeneity property: $m\left(\lambda x_{1}, \ldots, \lambda x_{N}\right)=\lambda m\left(x_{1}, \ldots, x_{N}\right)$ for all $\lambda>0$ and all $\left(x_{1}, \ldots, x_{N}\right)$ in the domain of definition.

33. Since $m$ is strictly increasing in each of its arguments, this can always be done.

34. Since unit cost functions must be linearly homogeneous, there is no constant term on the right hand side of (49). See Diewert [1993c; 122] for the properties of unit cost functions.

35. We are assuming that $N \geq 2$; i.e., that there is more than one commodity. There is no index number problem if $\mathbf{N}=1$.

36. For the case of a Leontief aggregator function, quantity vectors must be proportional across countries; for the case of a linear aggregator function, price vectors must be proportional across countries.

37. This fact was noted by Van Ijzeren [1983; 42] but he did not obtain the elegant formula (62) due to Dikhanov [1994].

38. Van Ijzeren [1983; 53] provided an elegant proof of the existence of a solution for the case of two countries. There does not appear to be a proof of existence in the general J case.

39. Turvey [1979] showed that Statistical Agency practices differed enormously in this situation and that very different sub annual indexes resulted from the same seasonal data set that he sent to Statistical Agencies.

40. For papers that incorporate consumer search into cost of living indexes, see Anglin and Baye [1987] and Reinsdorf [1993].

41. See Diewert [1995a] for references to the literature on aggregation at the lowest level. Fisher [1922; 318] casually endorsed the use of total quantities and unit values as the following quotation indicates: "On what principle should this average be constructed? The practical answer is any kind of average since, ordinarily, the variations during a year, so far, at least, as prices are concerned, are too little to make any perceptible difference in the result, whatever 
kind of average is used. Otherwise, there would be ground for subdividing the year into quarters or months until we reach a small enough period to be considered practically a point. The quantities sold will, of course, vary widely. What is needed is their sum for the year... In short, the simple arithmetic average, both of prices and of quantities, may be used. Or, if it is worth while to put any finer point on it, we may take the weighted arithmetic average for the prices, the weights being the quantities sold." What Fisher failed to emphasize is if the sum of quantities transacted is used as the quantity concept, then the unit value must be taken as the corresponding price concept in order to preserve the value of transactions within the period. Note that Fisher, like Hicks [1946; 122], defined the appropriate time period to be a time period during which variations in price can be neglected.

42. This is the current Statistical Agency approach; see Turvey $[1989 ; 50]$. The price quotes that are collected are regarded as being representative of all transaction prices for the commodity in the period under consideration.

43. Griliches [1979; 97], Gordon [1981] [1990] [1993], Griliches and Cockburn [1993] and Nordhaus [1994] discussed this type of bias and provided estimates of it in various situations. Diewert [1995a; 33] called this type of bias the "linking bias."

44. Hausman [1994] did this for new breakfast cereals.

45. See Diewert $[1980 ; 498-501]$.

46. Baldwin, Després, Nakamura and Nakamura [1994] survey how new goods are introduced into the producer price indexes of Canada and Japan. These authors also make the important point that a new good does not have to be new in the sense that the good did not exist anywhere in the world in the previous period but rather a new good is one which was not available in the local market in the previous period. This observation (which dates back to Marshall [1887; 374]) greatly widens the scope of the new goods problem and the possibility of bias in official indexes. 
47. Allen and Diewert [1981; 432-433] justify Hill's preference from a slightly different point of view: if price relatives have a small variance, then the conditions for Hicks' [1946; 312-313] Composite Commodity Theorm are approximately fulfilled and the price index should be constructed directly. On the other hand, if quantity relatives have a small variance, then the conditions for Leontief's [1936; 54-57] Aggregation Theorem are approximately satisfied and the quantity index should be constructed directly.

48. Diewert $[1980 ; 501]$ made this point in the context of evaluating the highest common factor method using the Hicksian [1940] reservation price methodology.

49. Denis Lawrence has used the above strategy quite successfully in Australia in comparing the productivity performance of government market oriented enterprises with each other and comparable best practice enterprises overseas; see Lawrence [1992] and the Industry Commission [1993].

50. See Jorgenson and Griliches [1967] and Christensen and Jorgenson [1970] for examples of how user costs can be calculated in a national income accounting framework. The user cost concept dates back to Walras [1874; 269] at least; see Jorgenson [1963] [1989], Diewert [1980; 475-486] and Griliches [1988] for more recent discussions of user costs. For a treatment of inventory user costs, see Diewert and Smith [1995].

51. The interest component of user cost could be treated in a manner analogous to Hill's proposed treatment of the depreciation component or the two components could be combined as in the Jorgenson and Griliches [1967] treatment of user cost.

52. For a theory of a real income deflator that is parallel to the Konüs [1924] cost of living deflator, see Diewert and Bossons [1987].

53. More specifically, take Pollak's [1989; 131] social cost of living index as the correct theoretical index. 
54. See Pollak [1989; 14]. The bias resulting from the use of $P_{L}$ of $P_{P}$ is the difference between the right and left hand sides of (11) or (12).

55. Recall the discussion of this method in section 7 above.

56. Recall our discussion of Hicks' $[1940 ; 114]$ approach to this problem in section 7 above.

57. This will still not eliminate the bias under normal conditions; i.e., the bias represented by the inequalities (70) and $(71)$ in section 7 will still remain.

58. Of course there are many exceptions; see for example Romer [1994] for a model of economic development that is centered around the creation of new goods.

59. See Kendrick [1961], Jorgenson and Griliches [1967], Christensen and Jorgenson [1970], Mark and Waldorf [1983], Balk [1994b] and Kohli [1990] [1993] for hints on how these accounts could be constructed.

60. See Eisner [1989] and Johal [1991].

61. See Hancock [1985], Barnett [1987], Fixler and Zieschang [1991] [1992] and Diewert and Smith [1995].

62. For a start, see Diewert [1995b]. 


\section{REFERENCES}

Afriat, S.N. [1972], "The Theory of International Comparisons of Real Income and Prices," pp. 13-69 in D.J. Daly (ed.), International Comparisons of Prices and Output, National Bureau of Economic Research, New York: Columbia University Press.

Afriat, S.N. [1977], The Price Index, London: Cambridge University Press.

Aizcorbe, A.M. and P.C. Jackman [1993], "The Commodity Substitution Effect in CIP Data, 198291," Monthly Labor Review (December), 25-33, U.S. Bureau of Labor Statistics.

Allen, R.C. and W.E. Diewert [1981], "Direct versus Implicit Superlative Index Number Formulae," The Review of Economics and Statistics 63, 430-435.

Allen, R.G.D. [1949], "The Economic Theory of Index Numbers, " Econometrica N.S. 16, 197-203. Allen, R.G.D. [1975], Index Numbers in Theory and Practice, London: Macmillan.

Anglin, P.M. and M.R. Baye [1987], "Information, Multiprice Search, and Cost-of-Living Index Theory," Journal of Political Economy 95, 1179-1195.

Archibald, R.B. [1977], "On the Theory of Industrial Price Measurement: Output Price Indexes," Annals of Economic and Social Measurement 6, 57-72.

Armknecht, P.A., B.R. Moulton and K.J. Stewart [1994], "Improvements to the Food at Home, Shelter and Prescription Drug Indexes in the U.S. Consumer Price Index, " paper presented at the International Conference on Price Indices, October 31-November 2, Ottawa: Statistics Canada.

Arrow, K.J. [1974], "The Measurement of Real Value Added, " pp. 3-19 in Nations and Households in Economic Growth, P.A. David and M.W. Reder (eds.), New York: Academic Press. Baldwin, A. [1985], The Treatment of Seasonal Commodities in the Consumer Price Index, Prices Division, Ottawa: Statistics Canada. 
Baldwin, A., P. Després, A. Nakamura and M. Nakamura [1994], "New Goods from the Perspective of Price Index Making in Canada and Japan," forthcoming in The Economics of New Goods, T. Bresnahan and R.J. Gordon (eds.), NBER, Cambridge, MA.

Balk, B.M. [1980a], "A Method for Constructing Price Indices for Seasonal Commodities, " Journal of the Royal Statistical Society A, 143, 68-75.

Balk, B.M. [1980b], Seasonal Products in Agriculture and Horticulture and Methods for Computing Price Indices, Statistical Studies 24, The Hague: Netherlands Central Bureau of Statistics.

Balk, B.M. [1989], "On Van Ijzeren's Approach to International Comparisons and its Properties," Statistical Papers (Statistische Hefte) 30, 295-315.

Balk, B.M. [1990], "On Calculating Cost-of-Living Index Numbers for Arbitrary Income Levels," Econometrica 58, 75-92.

Balk, B.M. [1993], "Multilateral Methods for International Price and Volume Comparisons," Department of Price Statistics, Netherlands Central Bureau of Statistics, P.O. Box 959, 2270 AZ, Voorburg, April.

Balk, B.M. [1994a], "On the First Step in the Calculation of a Consumer Price Index," paper presented at the International Conference on Price Indices, October 31-November 2, Ottawa: Statistics Canada.

Balk, B.M. [1994b], "Micro-Economic Foundations for Industrial Price, Quantity and Productivity Indices," paper presented at the Georgia Productivity Workshop, October 21-23; Statistics Netherlands, P.O. Box 959, 2270 AZ, Voorburg.

Balk, B.M. [1995], "Axiomatic Price Index Theory: A Survey," International Statistical Review 63, 75-92.

Barnett, W.A. [1987], "The Microeconomic Theory of Monetary Aggregation," pp. 115-168 in $\underline{\text { New }}$ Approaches to Monetary Economics, W.A. Barnett and K.J. Singleton (eds.), New York: Cambridge University Press. 
Bell, W.R. and C. Hillmer [1984], "Issues Involved with the Seasonal Adjustment of Economic Time Series," Journal of Business and Economic Statistics 2, 291-319.

Berndt, E.R. [1991], "The Measurement of Quality Change: Constructing a Hedonic Price Index for Computers Using Multiple Regression Methods," ch. 4 in E.R. Berndt, The Practice of Econometrics: Classic and Contemporary, Reading, MA: Addison-Wesley Press.

Berndt, E.R. and Z. Griliches [1993], "Price Indexes for Microcomputers: An Exploratory Study," pp. 63-93 in Price Measurements and Their Uses, M.F. Foss, M.E. Mansen and A.H. Young (eds.), Chicago: University of Chicago Press.

Berndt, E.R., Z. Griliches and J.G. Rosett [1993], "Auditing the Producer Price Index: Micro Evidence from Prescription Pharmaceutical Preparations," Journal of Business and Economic Statistics 11, 251-264.

Bjerke, K. [1968], "Some Reflections on the Terms of Trade," The Review of Income and Wealth $14,183-198$.

Bortkiewicz, L. von [1923], "Zweck und Struktur einer Preisindexzahl: Ester Artikel," Nordisk Statistisk Tidskrift 2, 369-408.

Bowley, A.L. [1901], Elements of Statistics, London: P.S. King and Son.

Bowley, A.L. [1921], "An Index of the Physical Volume of Production," Economic Journal 31, 196-205.

Caves, D.W., L.R. Christensen and W.E. Diewert [1982a], "Multilateral Comparisons of Output, Input and Productivity Using Superlative Index Numbers," The Economic Journal 92, 73-86.

Caves, D.W., L.R. Christensen and W.E. Diewert [1982b], "The Economic Theory of Index Numbers and the Measurement of Input, Output and Productivity," Econometrica 50, $1393-1414$.

Christensen, L.R. and D.W. Jorgenson [1970], "U.S. Real Product and Real Factor Input, 1929$1967, "$ Review of Income and Wealth 16, 19-50. 
Christensen, L., D. Jorgenson and L. Lau [1973], "Transcendental Logarithmic Production Frontiers," Review of Economics and Statistics 55, 28-45.

Cleveland, W.S. [1983], "Seasonal and Calendar Adjustment," pp. 39-72 in Handbook of Statistics, Vol. 3, Amsterdam: Elsevier Science Publishers.

Court, A.T. [1939], "Hedonic Price Indexes with Automotive Examples," pp. 98-119 in The Dynamics of Automobile Demand, New York: General Motors Corporation.

Crawford, A. [1993], "Measurement Biases in the Canadian CPI: A Technical Note," Bank of Canada Review, Summer, 21-36.

Dalén, J. [1992], "Computing Elementary Aggregates in the Swedish Consumer Price Index," Journal of Official Statistics 8, 129-147.

Davies, G.R. [1924], "The Problem of a Standard Index Number Formula, " Journal of the American Statistical Association 19, 180-188.

Davies G.R. [1932], "Index Numbers in Mathematical Economics," Journal of the American Statistical Association 27, 58-64.

Diewert, W.E. [1974], "Functional Forms for Revenue and Factor Requirements Functions," International Economic Review 15, 119-130.

Diewert, W.E. [1976], "Exact and Superlative Index Numbers," Journal of Econometrics 4, 115-145.

Diewert, W.E. [1978], "Superlative Index Numbers and Consistency in Aggregation, " Econometrica $46,883-900$.

Diewert, W.E. [1980], "Aggregation Problems in the Measurement of Capital," pp. 433-528 in The Measurement of Capital, Dan Usher (ed.), Chicago: University of Chicago Press.

Diewert, W.E. [1981], "The Economic Theory of Index Numbers: A Survey," pp. 163-200 in Essays in the Theory and Measurement of Consumer Behavior in Honour of Sir Richard Stone, A. Deaton (ed.), London: Cambridge University Press. 
Diewert, W.E. [1983a], "The Theory of the Cost-of-Living Index and the Measurement of Welfare Change," pp. 163-233 in Price Level Measurement, W.E. Diewert and C. Montmarquette (eds.), Ottawa: Statistics Canada.

Diewert, W.E. [1983b], "The Theory of the Output Price Index and the Measurement of Real Output Change," pp. 1049-1113 in Price Level Measurement, Ottawa, Statistics Canada.

Diewert, W.E. [1983c], "The Treatment of Seasonality in a Cost-of-Living Index, " pp. 1019-1045 in W.E. Diewert and C. Montmarquette (eds.), Price Level Measurement, Ottawa: Statistics Canada.

Diewert, W.E. [1986], Microeconomic Approaches to the Theory of International Comparisons," Technical Working Paper No. 53, National Bureau of Economic Research, Cambridge, Mass. Diewert, W.E. [1987], "Index Numbers," pp. 767-780 in The New Palgrave: A Dictionary of Economics, Volume 2, J. Eatwell, M. Milgate and P. Neuman (eds.), London: The Macmillan Press.

Diewert, W.E. [1988], "Test Approaches to International Comparisons, " pp. 67-86 in Measurement in Economics, W. Eichhorn (ed.), Heidelberg: Physica-Verlag.

Diewert, W.E. [1992a], "Fisher Ideal Output, Input and Productivity Indexes Revisited," The Journal of Productivity Analysis 3, 211-248.

Diewert, W.E. [1992b], "Exact and Superlative Welfare Change Indicators," Economic Inquiry 30, 565-582.

Diewert, W.E. [1993a], "The Early History of Price Index Research," pp. 33-65 in Essays in Index Number Theory, Volume 1, W.E. Diewert and A.O. Nakamura (eds.), Amsterdam: NorthHolland.

Diewert, W.E. [1993b], "Symmetric Means and Choice Under Uncertainty, " pp. 355-433 in Essays in Index Number Theory, Volume 1, W.E. Diewert and A.O. Nakamura (eds.), Amsterdam: North-Holland. 
Diewert, W.E. [1993c], "Duality Approaches to Microeconomic Theory," pp. 105-175 in Essays in Index Number Theory, Volume 1, W.E. Diewert and A.O. Nakamura (eds.), Amsterdam: North-Holland.

Diewert, W.E. [1995a], "Axiomatic and Economic Approaches to Elementary Price Indexes," Discussion Paper No. 95-01, Department of Economics, University of British Columbia, Vancouver, Canada V6T 1 Z1.

Diewert, W.E. [1995b], "Functional Form Problems in Modelling Insurance and Gambling," forthcoming in The Geneva Papers on Risk and Insurance Theory.

Diewert, W.E. and J. Bossons [1987], "Adjusting the Consumer Price Index for Changes in Taxes," Discussion Paper No. 87-09, Department of Economics, University of British Columbia, Vancouver, Canada, April.

Diewert, W.E. and C.J. Morrison [1986], "Adjusting Output and Productivity Indexes for Changes in the Terms of Trade," The Economic Journal 96, 659-679.

Diewert, W.E. and C.J. Morrison [1990], "Productivity Growth and Changes in the Terms of Trade in Japan and the United States," pp. 201-227 in Productivity Growth in Japan and the United States, C.R. Hulten (ed.), Chicago: University of Chicago Press.

Diewert, W.E. and A.M. Smith [1995], "Productivity Measurement for a Distribution Firm," Journal of Productivity Analysis, forthcoming.

Diewert, W.E. and T.J. Wales [1987], "Flexible Functional Forms and Global Curvature Conditions, " Econometrica 55, 43-68.

Dikhanov, Y. [1994], "Sensitivity of PPP Based Income Estimates to Choice of Aggregation Procedures," paper presented at the Conference of the International Association for Research in Income and Wealth, St. Andrews, New Brunswick, August.

Drechsler, L. [1973], "Weighting of Index Numbers in Multilateral International Comparisons, " The Review of Income and Wealth, Series 19 (March), 17-47. 
Dulberger, E.R. [1989], "The Application of a Hedonic Model to a Quality-Adjusted Price Index for Computer Processors," pp. 37-75 in Technology and Capital Formation, D.W. Jorgenson and R. Landau (eds.), Cambridge, Mass.: MIT Press.

Eichhorn, W. [1976], "Fisher's Tests Revisited," Econometrica 44, 247-256.

Eichhorn, W. [1978], Functional Equations in Economics, London: Addison-Wesley.

Eichhorn, W. and J. Voeller [1976], Theory of the Price Index, Lecture Notes in Economics and Mathematical Systems 140, Berlin: Springer-Verlag.

Eisner, R. [1989], The Total Incomes System of Accounts, Chicago: University of Chicago Press. Eltetö, O. and P. Köves [1964], "On a Problem of Index Number Computation Relating to International Comparison," Statisztikai Szemle 42, 507-518.

Eurostat [1988], Purchasing Power Parities and Gross Domestic Product in Real Terms: Results 1985, Luxembourg: Statistical Office of the European Communities.

Fisher, F.M. and K. Shell [1972], The Economic Theory of Price Indexes, New York: Academic Press.

Fisher, I. [1911], The Purchasing Power of Money, London: Macmillan.

Fisher, I. [1921], "The Best Form of Index Number," Journal of the American Statistical Association $17,533-537$.

Fisher, I. [1922], The Making of Index Numbers, First Edition, Boston: Houghton Mifflin Co.

Fisher, I. [1923], "Professor Bowley on Index-Numbers," (with discussion), The Economic Journal $33,246-252$.

Fixler, D.J. [1993], "The Consumer Price Index: Underlying Concepts and Caveats," Monthly Labor Review, BLS December, 3-12.

Fixler, D. and K.D. Zieschang [1991], "Measuring the Nominal Value of Financial Services in the National Income Accounts," Economic Inquiry 29, 53-68. 
Fixler D.J. and K.D. Zieschang [1992], "User Costs, Shadow Prices and the Real Output of Banks," pp. 219-243 in Output Measurement in the Service Sectors, Zvi Griliches (ed.), Chicago: University of Chicago Press.

Frisch, R. [1930], "Necessary and Sufficient Conditions Regarding the Form of an Index Number Which Shall Meet Certain of Fisher's Tests, " American Statistical Association Journal 25, 397-406.

Frisch, R. [1936], "Annual Survey of General Economic Theory: The Problem of Index Numbers," Econometrica 4, 1-39.

Geary, R.G. [1958], "A Note on Comparisons of Exchange Rates and Purchasing Power Between Countries," Journal of the Royal Statistical Society A, 121, 97-99.

Gerardi, D. [1982], "Selected Problems of Inter-Country Comparisons on the Basis of the Experience of the EEC," The Review of Income and Wealth 28, 381-405.

Gini, C. [1931], "On the Circular Test of Index Numbers," Metron 9:2, 3-24.

Gordon, R.J. [1981], "The Consumer Price Index: Measuring Inflation and Causing It," The Public Interest 63 (Spring), 112-134.

Gordon, R.J. [1989], "The Postwar Evolution of Computer Prices," pp. 77-125 in Technology and Capital Formation, D.W. Jorgenson and R. Landau (eds.), Cambridge, MA: MIT Press.

Gordon, R.J. [1990], The Measurement of Durable Goods Prices, Chicago: University of Chicago Press.

Gordon, R.J. [1993], "Measuring the Aggregate Price Level: Implications for Economic Performance and Policy." In Price Stabilization in the 1990s, K. Shigehara (ed.), London: Macmillan, 233-276.

Griliches, Z. [1961], "Hedonic Price Indexes for Automobiles: An Analysis of Quality Change," pp. 137-196 in The Price Statistics of the Federal Government, General Series No. 73, New York: Columbia University Press. 
Griliches, Z. [1971], "Introduction: Hedonic Prices Revisited," pp. 3-15 in Price Indexes and Quality Change, Z. Griliches (ed.), Cambridge, MA: Harvard University Press.

Griliches, Z. [1979], "Issues in Assessing the Contribution of Research and Development to Productivity Growth," The Bell Journal of Economics 10 (Spring), 92-116.

Griliches, Z. [1988], "Capital Stock in Investment Functions: Some Problems of Concept and Measurement," pp. 123-143 in Technology, Education and Productivity, Zvi Griliches (ed.), Oxford: Basil Blackwell.

Griliches, Z. and I. Cockburn [1994], "Generics and New Goods in Pharmaceutical Price Indexes," American Economic Review 84, 1213-1232.

Hamada, K. and K. Iwata [1984], "National Income, Terms of Trade and Economic Welfare," Economic Journal 94, 752-771.

Hancock, D. [1985], "The Financial Firm: Production with Monetary and Nonmonetary Goods," Journal of Political Economy $93,859-880$.

Hausman, J. [1994], "Valuation of New Goods Under Perfect and Imperfect Competition," forthcoming in The Economics of New Products, T. Bresnahan and R.J. Gordon (eds.), NBER, Cambridge, MA, April.

Hicks, J.R. [1940], "The Valuation of the Social Income," Economica 7, 105-140.

Hicks, J.R. [1946], Value and Capital, Second Edition, Oxford: Clarendon Press.

Hicks, J.R. [1981], Wealth and Welfare, Cambridge, MA: Harvard University Press.

Hill, P. [1982], Multilateral Measurements of Purchasing Power and Real GDP, Luxembourg: Eurostat.

Hill, P. [1984], "Introduction: The Special Conference on Purchasing Power Parities," Review of Income and Wealth, Series 30, 125-133.

Hill, P. [1988], "Recent Developments in Index Number Theory and Practice," O.E.C.D. Economic Studies 10 (Spring), 123-148. 
Hill, P. [1993], "Price and Volume Measures," pp. 379-406 in System of National Accounts 1993, Eurostat, IMF, OECD, UN and World Bank, Brussels, Luxembourg, New York and Washington D.C.

Hill, R.J. [1994a], "Chained Multilateral Comparisons Using Graph Theory Algorithms," Department of Economics, University of British Columbia, Vancouver, Canada, October.

Hill, R.J. [1994b], "A Taxonomy of Multilateral Methods for Making International Comparisons," Department of Economics, University of British Columbia, Vancouver, Canada, October. Hofsten, E. von [1952], Price Indexes and Quality Change, London: George Allen and Unwin. Hylleberg, S. (ed.) [1992], Modelling Seasonality, Oxford: Oxford University Press.

Iklé, D.M. [1972], "A New Approach to the Index Number Problem," The Quarterly Journal of Economics 86, 188-211.

Industry Commission [1993], Government Trading Enterprises Performance Indicators 1987-88 to 1991-92, P.O. Box 80, Belconnen ACT 2616, Australia.

Johal, K. [1991], "A Study of the Flow of Consumption Services from the Stock of Consumer Goods," National Income and Expenditure Accounts, 4th Quarter, Catalogue No. 13-001, 1-20, Ottawa: Statistics Canada.

Jorgenson, D.W. [1963], "Capital Theory and Investment Behavior," American Economic Review $53,247-259$.

Jorgenson, D.W. [1989], "Capital as a Factor of Production," pp. 1-35 in Technology and Capital Formation, D.W. Jorgenson and R. Landau (eds.), Cambridge, MA: MIT Press.

Jorgenson, D.W. and Z. Griliches [1967], "The Explanation of Productivity Change," Review of Economic Studies 34, 249-283.

Kendrick, J.W. [1961], Productivity Trends in the United States, Princeton: Princeton University Press.

Keynes, J.M. [1930], Treatise on Money, Vol. 1, London: Macmillan. 
Khamis, S.H. [1970], "Properties and Conditions for the Existence of a New Type of Index Number," Sankhya Series B 32, 81-98.

Khamis, S.H. [1972], "A New System of Index Numbers for National and International Purposes," Journal of the Royal Statistical Society, A, 135, 96-121.

Kohli, U. [1978], "A Gross National Product Function and the Derived Demand for Imports and Supply of Exports, " Canadian Journal of Economics 11, 167-182.

Kohli, U. [1990], "Growth Accounting in the Open Economy: Parametric and Nonparametric Estimates," Journal of Economic and Social Measurement 16, 125-136.

Kohli, U. [1991], Technology, Duality and Foreign Trade, Ann Arbor: University of Michigan Press.

Kohli, J. [1993], "GNP Growth Accounting in the Open Economy: Parametric and Nonparametric Estimates for Switzerland, Swiss Journal of Economics and Statistics 129, 601-615.

Konüs, A.A. [1924], "The Problem of the True Cost of Living, " translated in Econometrica 7, 139, $10-29$.

Konüs, A.A. and S.S. Byushgens [1926], "K Probleme Pokupatelnoi Cili Deneg," Voprosi Konyunkturi II:1, 151-172.

Kravis, I.B. [1984], "Comparative Studies of National Incomes and Prices," Journal of Economic Literature 22, 1-39.

Kravis, I.B., R. Summers and A. Heston [1982], "Comments on 'Selected Problems of Intercountry Comparisons on the Basis of the Experience of the EEC'," Review of Income and Wealth, Series $28,407-410$.

Kurabayashi, Y. [1971], "The Impact of Changes in Terms of Trade on a System of National Accounts: An Attempted Synthesis," The Review of Income and Wealth 17, 285-293.

Laspeyres, E. [1871], "Die Berechnung einer mittleren Waarenpreissteigerung," Jahrbücher für Nationalökonomie und Statistik 16, 296-314. 
Lawrence, D. [1992], Measuring the Total Factor Productivity of Government Trading Enterprises, Belconnen, Australia: Industry Commission.

Lehr, J. [1885], Beiträge zur Statistik der Preise, Frankfurt: J.D. Sauerländer.

Leontief, W. [1936], "Composite Commodities and the Problem of Index Numbers," Econometrica 4, 39-59.

Lowe, J. [1823], The Present State of England in Regard to Agriculture, Trade and Finance, Second Edition, London: Longman, Hurst, Rees, Orme and Brown.

Malmquist, S. [1953], "Index Numbers and Indifference Surfaces," Trabajos de Estatistica 4, 209-242.

Manser, M.E. and R.J. McDonald [1988], "An Analysis of Substitution Bias in Measuring Inflation, 1959-85," Econometrica 56, 909-930.

Mark, J.A. an W.H. Waldorf [1983], "Multifactor Productivity: A New BLS Measure," Monthly Labor Review (December), 3-15.

Marshall, A. [1887], "Remedies for Fluctuations of General Prices," Contemporary Review 51, 355-375.

Martini, M. [1992], "A General Function of Axiomatic Index Numbers," Journal of the Italian Statistical Society 3, 359-376.

Moulton, B.R. [1993], "Basic Components of the CPI: Estimation of Price Changes," Monthly Labor Review (December), 13-24, U.S. Bureau of Labor Statistics.

Nicholson, J.L. [1960], "The Effects of International Trade on the Measurement of Real National Income," Economic Journal 70, 608-612.

Nordhaus, W.D. [1994], "Do Real Output and Real Wage Measures Capture Reality? The History of Light Suggests Not," forthcoming in The Economics of New Goods, T. Bresnahan and R.J. Gordon (eds.), NBER, Cambridge, MA. 
Paasche, H. [1874], Über die Preisentwicklung der letzten Jahre nach den Hamburger Börsennotirungen, " Jahrbücher für Nationalökonomie und Statistik 23, 168-178.

Pollak, R.A. [1971], "The Theory of the Cost of Living Index," Research Discussion Paper 11, Bureau of Labor Statistics, Washington, D.C. and pp. 87-161 in W.E. Diewert and C. Montmarquette (eds.), Price Level Measurement, Ottawa: Statistics Canada, 1983.

Pollak, R.A. [1989], The Theory of the Cost-of-Living Index, Oxford: Oxford University Press. Reinsdorf, M. [1993], "The Effect of Outlet Price Differentials on the U.S. Consumer Price Index," pp. 227-254 in Price Measurements and Their Uses, M.F. Foss, M.E. Manser and A.H. Young (eds.), Studies in Income and Wealth, Vol. 57, NBER, Chicago: University of Chicago Press.

Reinsdorf, M. and B.R. Moulton [1994], "The Construction of Basic Components of Cost of Living Indexes," forthcoming in The Economics of New Goods, T. Bresnahan and R.J. Gordon (eds.), NBER, Cambridge, MA.

Romer, P. [1994], "New Goods, Old Theory and the Welfare Costs of Trade Restrictions," Journal of Development Economics 43, 5-38.

Ruggles, R. [1967], "Price Indexes and International Price Comparisons," pp. 171-205 in W. Fellner et al. (eds.), Ten Economic Studies in the Tradition of Irving Fisher, New York: John Wiley. Saglio, A. [1994], "Comparative Changes in Average Price and a Price Index: Two Case Studies," paper presented at the International Conference on Price Indices, October 31-November 2, Ottawa: Statistics Canada.

Samuelson, P.A. [1947], Foundations of Economic Analysis, Cambridge, MA: Harvard University Press.

Samuelson, P.A. and S. Swamy [1974], "Invariant Economic Index Numbers and Canonical Duality: Survey and Synthesis," American Economic Review 64, 566-593.

Sato, K. [1976], "The Meaning and Measurement of the Real Value Added Index," Review of Economics and Statistics 58, 434-442. 
Schultz (Szulc), B.J. [1994], "Choice of Price Index Formula at the Micro-Aggregation Level: The Canadian Empirical Evidence," paper presented at the International Conference on Price Indices, October 31-November 2, Ottawa: Statistics Canada.

Shephard, R.W. [1953], Cost and Production Functions, Princeton: Princeton University Press.

Sidgewick, H. [1883], The Principles of Political Economy, London: Macmillan.

Silver, M. and K. Mahdavy [1989], "The Measurement of a Nation's Terms of Trade Effect and Real National Disposable Income within a National Accounting Framework," Journal of the Royal Statistical Society, Series A 152, 87-107.

Stone, R. [1956], Quantity and Price Indexes in National Accounts, Paris: The Organization for European Cooperation.

Summers, R. and A. Heston [1988], "A New Set of International Comparisons of Real Product and Price Levels Estimates for 130 Countries, 1950-1988," Review of Income and Wealth, Series $34,1-25$.

Summers, R. and A. Heston [1991], "The Penn World Table (Mark 5): An Expanded Set of International Comparisons, 1950-1988," Quarterly Journal of Economics 106, 327-368.

Szilágyi, G. [1986], "Procedures for Linking International Comparisons," Statistical Journal of the United Nations ECE 4, 165-181.

Szulc, B.J. [1964], "Indices for Multiregional Comparisons," Przeglad Statystyczny (Statistical Review) 3, 239-254.

Szulc, B.J. [1983], "Linking Price Index Numbers," pp. 537-566 in Price Level Measurement, W.E. Diewert and C. Montmarquette (eds.), Ottawa: Statistics Canada.

Szulc, B.J. [1989], "Price Indices below the Basic Aggregation Level, " pp. 167-178 in Consumer Price Indices: An ILO Manual, R. Turvey (ed.), Geneva: International Labour Office.

Törnqvist, L. [1936], "The Bank of Finland's Consumption Price Index, " Bank of Finland Monthly Bulletin 10, 1-8. 
Triplett, J.E. [1986], "The Economic Interpretation of Hedonic Methods," Survey of Current Business 86:1, 36-40.

Triplett, J.E. [1987], "Hedonic Functions and Hedonic Indexes," pp. 630-634 in The New Palgrave: A Dictionary of Economics, Volume 2, J. Eatwell, M. Milgate and P. Newman (eds.), London: Macmillan.

Triplett, J.E. [1989], "Price and Technological Change in a Capital Good: A Survey of Research on Computers," pp. 127-213 in Technology and Capital Formation, D.W. Jorgenson and R. Landau (eds.), Cambridge, MA: MTT Press.

Triplett, J.E. [1992], "Economic Theory and BEA's Alternative Quantity and Price Indexes," Survey of Current Business 72 (April), 49-52.

Triplett, J.E. [1993], "Comment," pp. 197-206 in Price Measurements and Their Uses, M.F. Foss, M.E. Manser and A.H. Young (eds.), Studies in Income and Wealth, Vol. 57, The National Bureau of Economic Research, Chicago: The University of Chicago Press.

Turvey, R. [1979], "The Treatment of Seasonal Items in Consumer Price Indices," Bulletin of Labour Statistics, 4th quarter, International Labour Office, Geneva, 13-33.

Turvey, R. [1989], Consumer Price Indices: An ILO Manual, Geneva, Switzerland: International Labour Office.

United Nations [1993], System of National Accounts 1993, New York: United Nations.

United States Büreau of Labor Statistics [1983], Trends in Multifactor Productivity 1948-81, Bulletin 2178, Washington, D.C.: U.S. Government Printing Office.

United States Bureau of Labor Statistics [1993], Labor Composition and U.S. Productivity Growth. 1948-90, Bulletin 2426, Washington D.C.: U.S. Government Printing Office.

Van Ijzeren, J. [1983], Index Numbers for Binary and Multilateral Comparison, Statistical Studies No. 34, The Hague: The Netherlands Central Bureau of Statistics. 
Van Ijzeren, J. [1987], Bias in International Index Numbers: A Mathematical Elucidation, Eindhoven: Dissertatiedrukkerij Wibro.

Van Yzeren, J. [1956], Three Methods of Comparing the Purchasing Power of Currencies, Statistical Studies No. 7, The Hague: The Netherlands Central Bureau of Statistics.

Van Yzeren, J. [1988], "Weighting and Additivity Problems of Multilateral Comparison, " pp. 157164 in Measurement in Economics, W. Eichhorn (ed.), Heidelberg: Physica-Verlag.

Wald, A. [1939], "A New Formula for the Index of Cost of Living," Econometrica 7, 319-331.

Walras, L. [1874], Elements of Pure Economics, translated by William Jaffé [1954], London: George Allen and Unwin.

Walsh, C.M. [1901], The Measurement of General Exchange Value, New York: Macmillan and Co.

Walsh, C.M. [1921a], The Problem of Estimation, London: P.S. King and Son.

Walsh, C.M. [1921b], "Discussion of the Best Form of Index Number," Journal of the American Statistical Association 17, 537-544.

Walsh, C.M. [1924], "Professor Edgeworth's Views on Index-Numbers," Quarterly Journal of Economics 38, 500-519.

Wold, H. [1944], "A Synthesis of Pure Demand Analysis, Part III," Skandinavisk Aktuarietidskrift $27,69-120$.

Wynne, M.A. and F.D. Sigalla [1994], "The Consumer Price Index," Economic Review Federal Reserve Bank of Dallas, Second Quarter, 1-22.

Young, A.H. [1992], "Alternative Measures of Change in Real Output and Prices," Survey of Current Business 72 (April), 32-48. 